\title{
The Prediction of Isothermal Cyclic Plasticity in 7175-T7351 Aluminium Alloy with Particular Emphasis on Thermal Ageing Effects
}

\author{
M. F. Lam Wing Cheong ${ }^{1}$, J. P. Rouse ${ }^{2}$, C. J. Hyde ${ }^{2}$, and A. R. Kennedy ${ }^{3}$ \\ ${ }^{1}$ SMT, Chartwell House, 67 Hounds Gate, Nottingham, NG1 6BB \\ ${ }^{2}$ Gas Turbine and Transmissions Research Centre (G2TRC), Faculty of Engineering, \\ University of Nottingham, NGr 2TU, UK \\ ${ }^{3}$ Engineering Department, Lancaster University, LA1 4WY, UK
}

\begin{abstract}
Rapid thermal ageing has been observed in the literature for certain aerospace aluminium alloys under conditions which are foreseeable in their intended component applications. While several experimental programs have explored this phenomenon in the laboratory, efforts to incorporate these effects in unified constitutive models have, to date, been lacking. In the present work, a modified elastic-viscoplastic material model has been fitted to 7175-T7351 aluminium alloy data under fully-reversed uniaxial (straincontrolled) isothermal loading conditions at $160^{\circ} \mathrm{C}$ and $200^{\circ} \mathrm{C}$. These temperatures were chosen in order to represent nominal and extreme (but still operationally relevant) conditions experienced by aero-engine gearbox components. The modified elastic-viscoplastic model is able to accurately predict the hysteresis loops of the strain-controlled fatigue data of each sample at $160^{\circ} \mathrm{C}$ and $200^{\circ} \mathrm{C}$. Additionally, it was found that the isotropic hardening can be effectively de-coupled into material ageing and mechanical softening components.
\end{abstract}

\section{Introduction}

The Advisory Council for Aviation Research and Innovation in Europe (ACARE) aim to reduce $\mathrm{CO}_{2}$ emissions per passenger kilometre by $75 \%$ and NOx emissions by $90 \%$ by the year 2050 , in relation to the year 2000 emission records. One way to improve the specific fuel consumption is to reduce the weight of the aircraft. This would result in less fuel being consumed and less emissions being produced [1]. Both cast aluminium and titanium alloys are currently used for aero-engine gearbox housing applications, with the former offering comparatively low density and moderate yield and fatigue strength properties. 7000 series alloys are usually used for structural components such as aircraft wing, airframe and fuselage applications because of their remarkable combination of low density, high yield strength and fatigue strength, and easy formability [2]. If aluminium materials can be demonstrated to be suitable for housing applications, then reductions in component weight of around $40 \%$ could be achieved[3], along with estimated reductions in manufacturing costs of approximately $60 \%$. The use of aluminium alloys for this application is however limited at elevated temperatures due to the detrimental evolution of the alloys metastable microstructure. Elevated temperatures in the present context may be considered, at 
a maximum, to be $200^{\circ} \mathrm{C}$. Temperatures of this magnitude may be experienced in operation for short periods of time in "freak" events in a flight cycle. Although significant mechanical load is not expected in gearbox housings, severe thermal gradients can develop during operation. These are often cyclic in nature, thereby legitimising concerns over low cycle fatigue. It is well documented that exposure to elevated temperatures can facilitate the coarsening of precipitates (material ageing) which can be detrimental to the material's strength $[4,5])$.

Unified viscoplasticity models that describe material response on the macroscopic scale have been famously developed by Chaboche and Rousslier [6], and have been shown (in the literature) of being capable of predicting complex material behaviour such as non-linear kinematic and isotropic hardening, the Bauschinger effect [7], and viscous effects due to stress relaxation. Researchers such as Marquis and Lemaitre [8], and Cailletaud et al [9] have successfully incorporated the material ageing behaviour of under-aged aluminium alloys (2024 alloy that was aged at room temperature after quenching and the cast aluminium alloy ASTM 319 used for cylinder head, respectively) into their constitutive models. Marquis [8] modelled the ageing behaviour based on how the yield strength changed with time at room temperature and accounting for the effects of prior monotonic and accumulated plastic strain on the ageing rate and saturated ageing level. Cailletaud [9] modelled the ageing behaviour from hardness testing. Exposing the ASTM 319 alloy to greater exposure temperatures produced more significant initial rates of decreasing hardness to lower asymptotic hardness levels. Although models such as these are applicable to 7175-T7351 room temperature testing is often used to derive ageing related material parameters. In the present work all testing is conducted at elevated temperature and novel waveforms are designed which highlight combined plasticity and ageing effects.

Investigations into simultaneous material ageing and hardening using standard (constant amplitude) loading waveforms makes data interpretation difficult (or, at least, more difficult than it needs to be). Under isothermal conditions, it is easy to intuit a situation where a material is response is initially elastic (i.e. imposed strain limits are insufficient to cause appreciable plasticity in the hysteresis loops) until exposure is sufficient to lower the material's yield stress to a point where plasticity is observed. Alternatively, if strain limits are too large, hysteresis loops may quickly expand as the material ages, thereby offering only a limited number of result cycles before failure. Strain control is clearly beneficial as specimen gauge sections remain nearly constant throughout the test and approximately equal compressive and tensile loads may be imparted on the sample, however the inclusion of ageing effects in results makes the partitioning of data problematic.

This paper presents a modified unified, uniaxial viscoplasticity "Chaboche" type model to predicted material behaviour under fully-reversed isothermal fatigue conditions, accounting for the material ageing behaviour at gearbox housing operating temperatures for a 7175-T7351 (an overaged aluminium alloy). In the present work, material model constants are developed for a uniaxial viscoplasticity model using a novel "decaying amplitude" strain waveform. This ensures an appreciable amount of plasticity is accumulated in all loading cycles while not overstraining the material in its initial ("virgin") state.

\section{Material and Experimental Procedure}

\subsection{Material}

A wrought 7175 aluminium alloy, heat treated to the T7351 specification according to the SAE AMS2772F procedure, in the form of $1.5 \times 1.0 \times 0.03 \mathrm{~m}$ hot rolled plate is used in the present work. This material is a candidate for next generation of aero-engine gearbox housings. Investigations into hardness variations in both the rolled and transverse directions revealed negligible dependency. Readers should note however that all samples presented here were extracted with the rolled direction perpendicular to the specimen's 
axis. The chemical composition of this alloy can be seen in Table 2.1.

Table 2.1: Element composition of the 7175-T7351 aluminium alloy.

\begin{tabular}{ccccccccccc}
\hline & $\mathrm{Zn}$ & $\mathrm{Mg}$ & $\mathrm{Cu}$ & $\mathrm{Cr}$ & $\mathrm{Ti}$ & $\mathrm{Fe}$ & $\mathrm{Mn}$ & $\mathrm{Si}$ & Other & $\mathrm{Al}$ \\
\hline wt $\%$ & 5.7 & 2.5 & 1.6 & 0.2 & 0.04 & 0.06 & 0.02 & 0.03 & 0.02 & $\mathrm{Bal}$ \\
\hline
\end{tabular}

\subsection{Specimen Design}

The present work draws upon experimental data generated using several specimen types. These results look to identify/characterise phenomenological relationships (related to thermal ageing, viscoplastic stress relaxation, and mechanical hardening) by applying a variety of loading conditions, thereby offering a route for the development and validation of an ageing sensitive unified (viscoplastic) material model. Tensile, or monotonic, testing is performed here in order to determine yield stresses in thermally aged samples (relevant "dog bone" type specimens may be seen in figure 2.1). These results establish the relationship between exposure time (at temperature) and the initial size of a yield locus, thereby allowing for the production of a novel decaying amplitude loading waveform. Cyclic plasticity tests are conducted here in order to demonstrate hardening/ageing in virgin/partially thermally aged material (see figure 2.2) for material parameter determination and validation. Stress relaxation tests (wherein a specimen is held at a constant total strain and the reduction is stress in monitored) are used in the present work to estimate viscous material parameters (assuming a power law flow rule) in the unified model. Related specimen designs are shown in figure 2.3 .

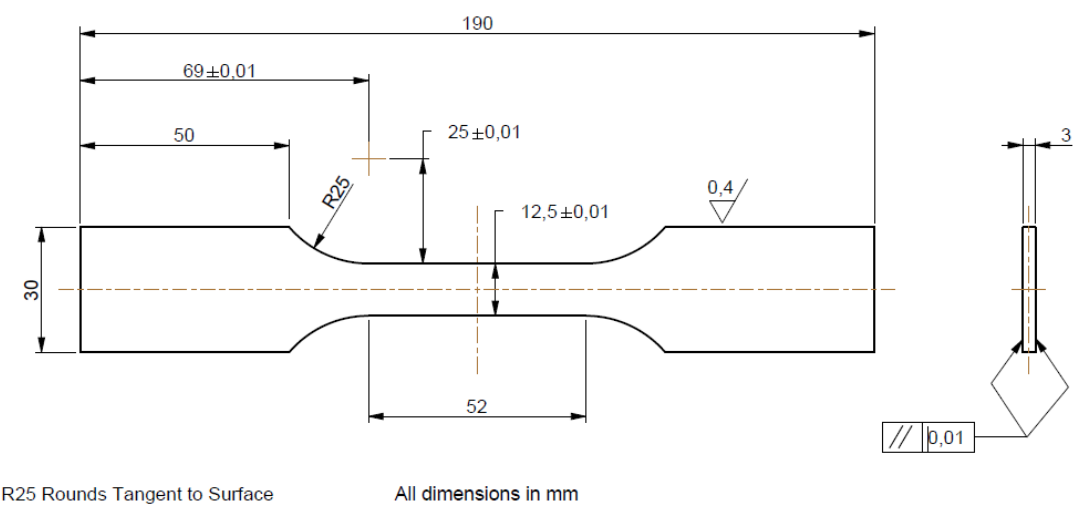

Figure 2.1: Tensile test sample geometry.

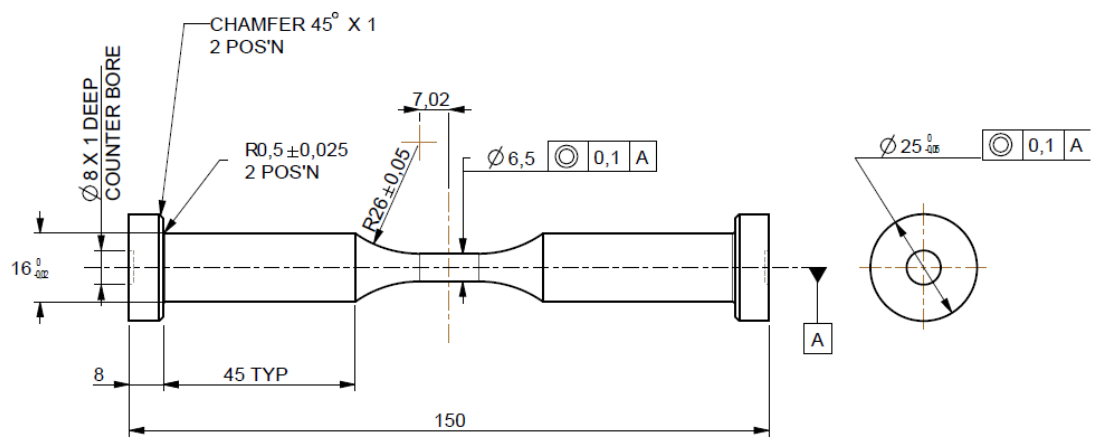

All dimensions in $\mathrm{mm}$

Figure 2.2: Isothermal fatigue sample geometry. 


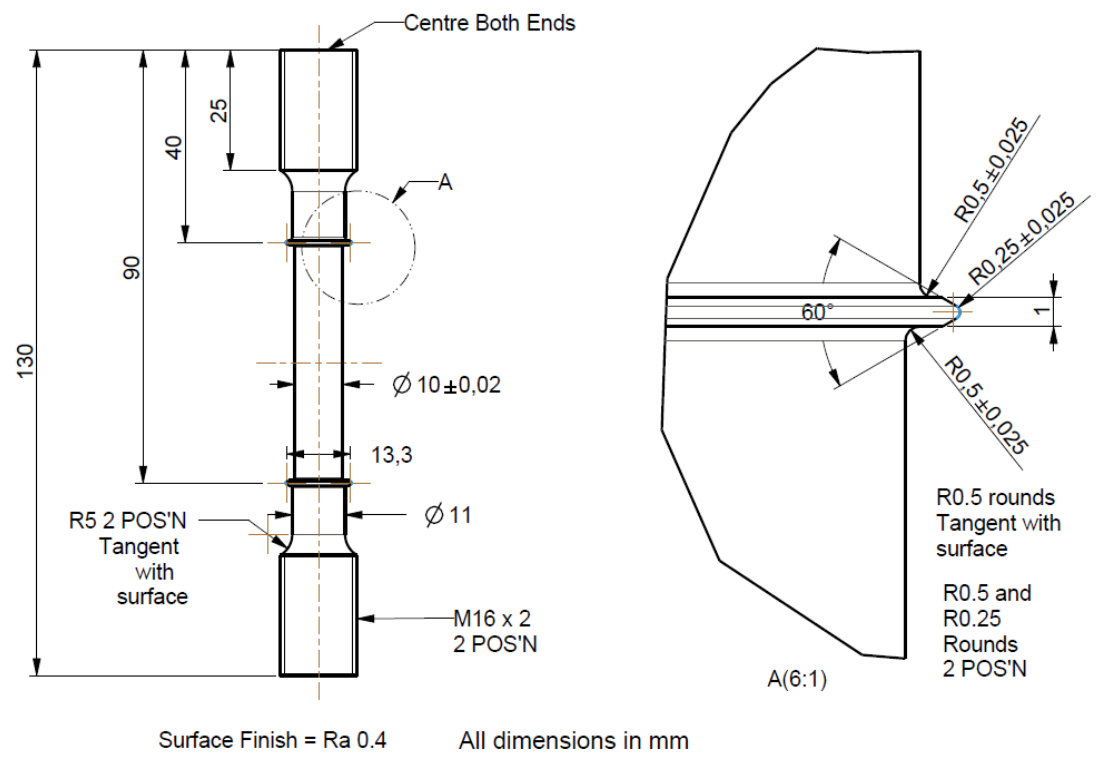

Figure 2.3: Stress relaxation test sample geometry.

\subsection{Experimental Procedures}

An Instron 5985 was used to conduct the elevated temperature tensile (monotonic) tests within a three zone environmental chamber (used for temperature control). The maximum permissible temperature difference along the length of the gauge section was $\pm 3^{\circ} \mathrm{C}$, and the permissible difference between the test sample and the test temperature was $\pm 3^{\circ} \mathrm{C}$ which was in accordance to the standard BS EN ISO 68922:2011. All samples were loaded in tension at a rate of $1 \mathrm{~mm} \cdot \mathrm{min}^{-1}$. Non-contact strain measurement was achieved using an Imetrum video gauge. Test specimens were coated with a white boron nitride spray and speckled with black spray paint to give them distinguishable features that could be tracked by the video gauge for strain measurement. As discussed previously, monotonic testing is used here in order study the effects of thermal ageing (exposure at elevated temperature) on the yielding behaviour of 7175 aluminium alloy. The test specimens were also soaked at $160^{\circ} \mathrm{C}$ and $200^{\circ} \mathrm{C}$ for up to 1000 hours before testing at their respective soak temperatures. It is recognised by the authors that this introduces a thermal cycle in the specimen, however the effects due to this feature in the material history are assumed to be negligible as the time periods associated with these cycles are relatively small (of the order to 20 minutes) compared to the tested exposure times. The results of these tests are presented later in this work (as they related directly to the generation of a novel decaying amplitude waveform, see figure 2.5), however relationships may be established here that related "yield strain" (i.e. that strain at which yielding in considered to have commenced in the uniaxial monotonic tests, determined though a linear regression type analysis) and exposure time. The fitting equation given in equation 2.1 is assumed here to describe this relationship.

$$
\varepsilon_{y}(t)=\varepsilon_{y 0}+A(1-\exp (-B t))+D t
$$

In equation $2.1, \varepsilon_{y}$ is taken as the instantaneous monotonic yield strain (at time $t$ ), $\varepsilon_{y_{0}}$ is the initial monotonic yield strain (for the virgin material, i.e. before any exposure), and $A, B$, and $D$ are material dependent fitting constants. Values for $A, B$, and $D$ were determined using in built MATLAB functionality (namely the nonlinear least squares optimisation algorithm LSQNONLIN) and are presented for soak/test temperatures of $160^{\circ} \mathrm{C}$ and $200^{\circ} \mathrm{C}$ (see table 2.2) . 
Using the relationship developed in equation 2.1, a novel fully reversed triangular waveform of decreasing strain amplitude was designed for isothermal cyclic plasticity testing testing. That is to say, strain amplitudes are adjusted on a cycle by cycle basis and proportional to the total exposure time at temperature. Peak strain values in any particular loading cycle were limited to $\varepsilon_{y}+10 \%$, based on the instantaneous value of $\varepsilon_{y}$ at the beginning of a particular loading cycle (see figure 2.4). It is intended here that this decaying waveform will allow for the study of cyclic plasticity in a rapidly ageing material using well known post-processing techniques as an appreciable amount of plasticity can be accumulated in each loading cycle. It is worth noting here that there is a danger in constant amplitude strain controlled tests as, if strain limits are too low, material response will be almost entirely elastic for the first loading cycles (until ageing effects reduce the yield condition such that plasticity can be observed). If strain limits are too high on the other hand stresses in the later loading cycles (i.e. once the material has significantly aged) may exceed the material's ultimate tensile strength (UTS), leading to rapid failure and preventing the study of plasticity in a stabilised material.

Table 2.2: A summary of coefficients, used in equation 2.1, which describe the effect of exposure time on yield strain (for 7175-T7351 aluminium alloy). Soak/test temperatures used here are $160^{\circ} \mathrm{C}$ and $200^{\circ} \mathrm{C}$.

\begin{tabular}{|c|c|c|c|c|}
\hline Temperature $\left({ }^{\circ} \mathrm{C}\right)$ & $\varepsilon_{y 0}$ & $A$ & $B$ & $D$ \\
\hline 160 & 0.5285 & -0.2193 & 0.0218 & $-7.12 \mathrm{E}-06$ \\
200 & 0.4485 & -0.2139 & 0.0828 & $-6.51 \mathrm{E}-05$ \\
\hline
\end{tabular}

Strain-controlled isothermal cyclic plasticity tests were (using the decaying amplitude waveform generated using the method above) conducted using an Instron 8862 TMF thermomechanical fatigue system and heated using a radio-frequency induction furnace. An extensometer was used for sample strain measurement. Thermocouples could not be spot welded to the aluminium alloy for temperature measurement. Therefore, a CTLF-CF2-C8 high performance pyrometer was used for non-contact thermal measurements. Fatigue samples were lightly abraded in the direction of loading with P4000

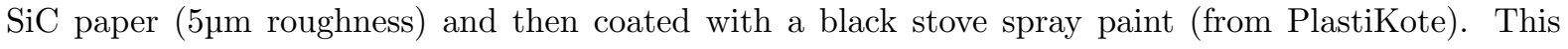
was to obtain a consistent emissivity value of the sample for temperature measurement using the pyrometer (a value of 0.88 was used for all samples).

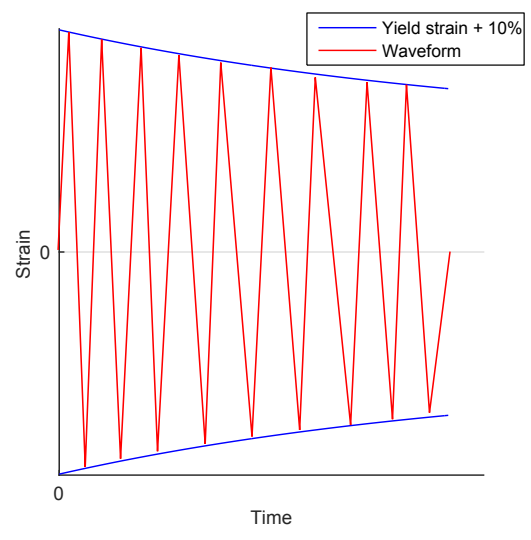

Figure 2.4: Ideal fully reversed load profile for the strain-controlled fatigue tests.

In the order to create a practically implementable decaying amplitude waveform, multiple "test blocks" of constant strain amplitude were programmed. Successive test blocks where generated for increasingly lower strain amplitudes, ultimately leading to a stabilised strain amplitude (acheived when 
the material has ceased to thermally age). The maximum strain of each test block is represented by the red "stepped" line in figure 2.5. The termination of a test block occurred when the applied strain was $+0.5 \%$ greater than the desired strain profile represented by the blue dashed curve (this line may be thought of as the ideal decaying strain amplitude profile). A constant loading (strain) rate was applied in all cyclic plasticity tests, namely $5 \mathrm{E}-03 \% . \mathrm{s}^{-1}$ (the present work does not look to quantify loading rate dependencies outside those observed in stress relaxation tests). It is worth noting here that, in a test with a decaying loading amplitude, applying a constant loading rate would imply a decaying cycle period (a cycle's period being directly proportional to it's amplitude). The decaying strain amplitude waveform may therefore be thought of as a variable frequency test, however it must be emphasised that loading rate is constant throughout.

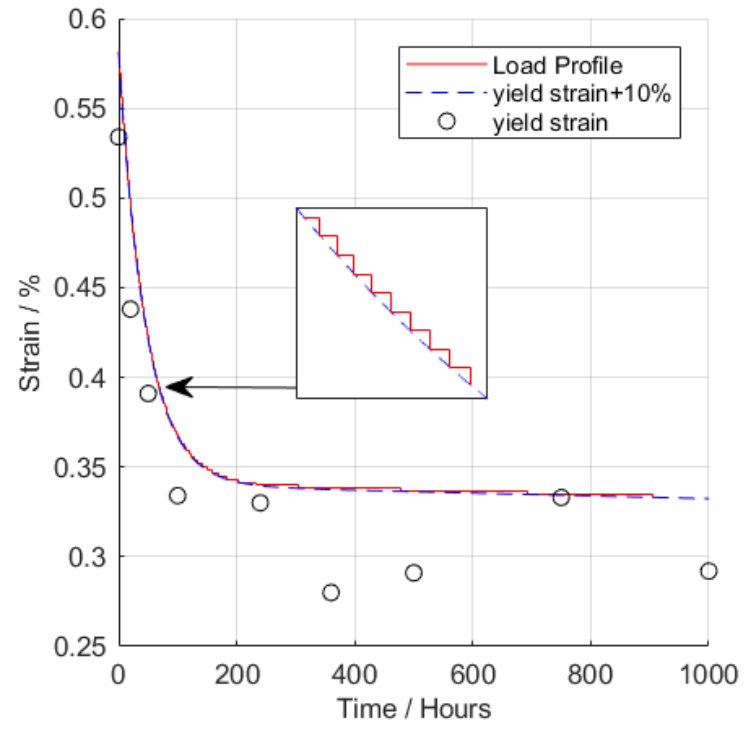

(a)

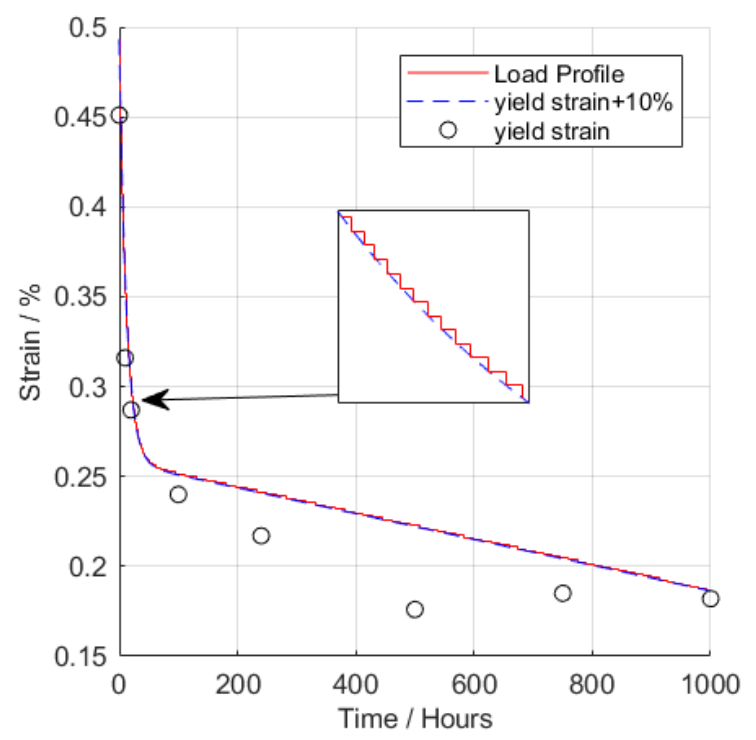

(b)

Figure 2.5: The load profile at (a) $160^{\circ} \mathrm{C}$ and (b) $200^{\circ} \mathrm{C}$. The red stepped line represents the duration at a certain amplitude before stepping down.

In all cyclic plasticity testing, the maximum allowable (indicated) axial temperature variation over the gauge section was $\pm 10^{\circ} \mathrm{C}$ (note that this is within the tolerances specified in BS ISO 12111-2011). As in tensile monotonic testing, cyclic plasticity specimens were tested at $160^{\circ} \mathrm{C}$ and $200^{\circ} \mathrm{C}$. Specimens were tested in virgin (i.e with no prior thermal ageing or exposure to elevated temperature) and aged states (i.e. with some exposure to the test temperature condition prior to mechanical loading). For clarity, specimens were soaked at $160^{\circ} \mathrm{C}$ and $200^{\circ} \mathrm{C}$ for 0 hours, 75 hours, 100 hours or 400 hours. A test name convention is used in the present work, with designations indicating the soak temperature (" $160^{\circ} \mathrm{C}$ " or " $200^{\circ} \mathrm{C} "$ ) and soak time in hours ("0h", " $75 \mathrm{~h} "$, " $100 \mathrm{~h} "$ or " $\left.400 \mathrm{~h} "\right)$. A summary of test conditions for each sample can found in Table 2.3 .

Stress relaxation tests were conducted to inform viscous stress parameters in the unified viscoplastic model developed here. Test specimens were soaked at $160^{\circ} \mathrm{C}$ or $200^{\circ} \mathrm{C}$ for 400 hours before testing at the respective soak temperature. The specimens were strained at a rate of $5 \mathrm{E}-03 \% . \mathrm{s}^{-1}$ to $\varepsilon_{y}+10 \%$ for a dwell period of 2 hours. The deviation in specimen temperature was within $\pm 3^{\circ} \mathrm{C}$ of the specified test temperature and along the gauge length, which is in accordance to BS EN ISO 204:2009. 
Table 2.3: Strain-controlled isothermal fatigue test matrix

\begin{tabular}{|c|c|c|c|c|}
\hline Sample ID & $\begin{array}{c}\text { Soak Time } \\
(\text { Hours })\end{array}$ & $\begin{array}{c}\text { Test and Soak Temperature } \\
\left({ }^{\circ} \mathrm{C}\right)\end{array}$ & $\begin{array}{c}\text { Frequency } \\
(\mathrm{Hz})\end{array}$ & Strain Ratio \\
\cline { 1 - 2 } $160^{\circ} \mathrm{C}-0 \mathrm{~h}$ & 0 & \multirow{2}{*}{160} & & \\
\cline { 1 - 2 } $160^{\circ} \mathrm{C}-100 \mathrm{~h}$ & 100 & \multirow{2}{*}{ Variable } & -1 \\
\cline { 1 - 2 } $160^{\circ} \mathrm{C}-400 \mathrm{~h}$ & 400 & \multirow{2}{*}{200} & & \\
\cline { 1 - 2 } $200^{\circ} \mathrm{C}-0 \mathrm{~h}$ & 0 & & & \\
\cline { 1 - 2 } $200^{\circ} \mathrm{C}-75 \mathrm{~h}$ & 75 & & & \\
\cline { 1 - 2 } $200^{\circ} \mathrm{C}-400 \mathrm{~h}$ & 400 & & & \\
\hline
\end{tabular}

\section{The Modified Uniaxial, Viscoplasticity Chaboche Model}

\subsection{Constitutive Equations}

Several important assumptions are made in the present work regarding the interaction between mechanical (hardening/softening) and ageing effects, principally that ageing acts to reduce the size of the yield locus isotropically (through the time dependent accumulation of drag stress) and that hardening and ageing mechanisms may be linearly decomposed (i.e. there is no coupling between drag stress accumulation due to ageing effects and mechanical straining). Here, a unified elastic viscoplastic material model (based on the work of Chaboche[6, 10]) is used to describe temperature dependent stress-strain behaviour of the 7175-T7351 aluminium alloy. Discussions are here limited to the uniaxial case, however it is intended that future work will look to develop the model presented here to the multi-axial case (using well known generalisations of the state/conjugate variable evolution equations) and validate it against experimental data.

Total strain $\left(\varepsilon_{\text {total }}\right)$ may be decomposed into elastic (recoverable, $\varepsilon_{e}$ ) and viscoplastic (time dependent and irrecoverable, $\varepsilon_{p}$ ) components, see equation 3.1.

$$
\varepsilon_{\text {total }}=\varepsilon_{e}+\varepsilon_{p}
$$

For an elastic-plastic material, a yield function $(f)$ may be defined (see equation 3.2) which is equal to the 0 at yield. In this function, the initial yield locus size $(k)$ is modified by the evolving drag stress $(R$, a scalar that acts to reduce the size of the yield locus) and the back stress ( $\chi$, a scalar in the uniaxial formulation which adjusts the centre of the yield locus). For viscoplastic applications, $f$ may be equated to the viscous (time dependent) stress, with the plastic strain rate $\left(\dot{\varepsilon}_{p}\right)$ determined through a flow rule relationship. In the present work, a power law flow rule is assumed, leading to equation 3.3 (where the sgn function is defined by equation 3.4).

$$
\begin{aligned}
& f=|\sigma-\chi|-R-k \\
& \dot{\varepsilon}_{p}=\left\langle\frac{f}{Z}\right\rangle^{n} \operatorname{sgn}(\sigma-\chi) \\
& \operatorname{sgn}(x)=\left\{\begin{array}{ll}
1 & x>0 \\
0 & x=0 \\
-1 & x<0
\end{array} \text { and }\langle x\rangle= \begin{cases}x & x \geq 0 \\
0 & x<0\end{cases} \right.
\end{aligned}
$$


$R$ is the isotropic drag stress that determines the expansion or reduction of the yield surface. It is assumed here that the isotropic hardening/softening can be de-coupled into mechanical softening (due to the accumulation of plastic strain), $R_{m}$ (see equation 3.6), and material ageing, $R_{a}$, as shown in equation 3.5. Note that $p$ is the (scalar) accumulated plastic strain (see equation 3.7). Equation 3.8 determines an additional stress required to accurately describe the material's yield stress at time $t$ before the microstructure stabilises (due to the effects of ageing).

$$
\begin{gathered}
R=R_{m}+R_{a} \\
R_{m}=Q_{m}\left(1-e^{-b_{m} p}\right)+H_{m} p \\
\dot{p}=\left|\dot{\varepsilon_{p}}\right| \\
R_{a}=Q_{a 1} e^{b_{a 1} t}+Q_{a 2} e^{b_{a 2} t}
\end{gathered}
$$

$\chi$ is the total back stress due to kinematic hardening. In order to characterise both long and short term kinetic hardening (i.e. with multiple hardening and dynamic recovery rates), back stress was decomposed into multiple Armstrong and Frederick [11] type components (see 3.9). $M$ is the total number of back stresses and $\dot{\chi}_{i}$ represents the rate at which the $i_{t h}$ back stress component saturates. Each back stress is dependent on the material parameters $C_{i}$ and $a_{i}$ (see equation equation 3.10). Previous work has shown that 2 back stresses $(M=2)$ are commonly sufficient for the description of both short term and long term dynamic recovery effects (represented by $\chi \dot{p}$ ) [12-14], provided that the description of cyclic plasticity rather than ratcheting is the main objective. Focus has therefore been limited to 2 back stress components in the present work.

$$
\begin{gathered}
\chi=\Sigma_{i}^{M} \chi_{i} \\
\dot{\chi}_{i}=C_{i}\left(a_{i} \dot{\varepsilon}_{p}-\chi \dot{p}\right)
\end{gathered}
$$

Total stress may be expressed through equation 3.11. $\sigma_{v}$ is the viscous stress, described by a power law in equation 3.12. $a_{i}, C_{i}, Z, n, H_{m}, b_{m}$ and $Q_{m}$ are temperature-dependent material parameters which describe hardening/viscous behaviour due to the accumulation of plastic strain, whereas $Q_{a}, b_{a}, Q_{a 2}$ and $b_{a 2}$ are temperature-dependent material parameters which describe ageing behaviour.

$$
\begin{gathered}
\sigma=\chi+\left(R+k+\sigma_{v}\right) \operatorname{sgn}(\sigma-\chi)=E\left(\varepsilon-\varepsilon_{p}\right) \\
\sigma_{v}=Z \dot{p}^{1 / n}
\end{gathered}
$$

\subsection{Determination of Initial Material Parameters}

Initial estimates of temperature dependent material parameters parameters are obtained in the present work by partitioning experimental hysteresis loops using well known techniques. Subsequent optimisation procedures are implemented using the Levenberg-Marquardt method [15] (LSQNONLIN in MATLAB) to fine tune material parameters. This method interpolates between the Gauss-Newton method and the steepest descent method to reduce computational time. The ordinary differential equations within the Chaboche model are solved using the function ODE45. 


\subsubsection{Initial Cyclic Yield Stress and Young's Modulus}

In the present work, $k$ (the initial cyclic yield strength) may be thought of as the yield strength of the material when its microstructure has stabilised (i.e. there no capacity for further thermal ageing and $R_{a} \rightarrow 0$ ). The results of monotonic tensile tests suggest that, for both $160^{\circ} \mathrm{C}$ and $200^{\circ} \mathrm{C}$ soak/test temperatures (see figure 2.5), this occurs after 400 hours of exposure at elevated temperature. Consequently $k$ and Young's modulus $(E)$ were determined using data from cyclic plasticity tests for samples that had been prior aged for 400 hours ( data designated " $160^{\circ} \mathrm{C}-400 \mathrm{~h} "$ and " $200^{\circ} \mathrm{C}-400 \mathrm{~h}$ "). Specifically, the first cycle from each of these tests was portioned using Cottrell's method (see section 3.2.2), thereby defining an elastic region from which $k$ and $E$ could be estimated.

\subsubsection{Mechanical Softening Parameters}

Samples that were soaked for 400 hours at $160^{\circ} \mathrm{C}$ and $200^{\circ} \mathrm{C}$ were assumed to have thermally stable microstructures. As a result of this, it was reasoned that any change in drag stress that was observed in cyclic plasticity tests using "thermally stable" samples was solely due to mechanical softening (representing the evolution of $R_{m}$ in the present work's context). Material parameters related to $R_{m}$ were therefore obtained from the material data of test specimens $160^{\circ} \mathrm{C}-400 \mathrm{~h}$ and $200^{\circ} \mathrm{C}-400 \mathrm{~h}$. Experimental values for $R_{m}$ were estimated (on a cycle by cycle basis) using Cottrell's stress partitioning method, where the yield surface radius, $\frac{\sigma_{e l}}{2}$, is the sum of $R_{m}+k$ (equation 3.13).

$$
\frac{\sigma_{e l}}{2}=R_{m}+k
$$

The parameter $H_{m}$ was determined by finding the gradient secondary linear region of the drag stress evolution series (determined using the Cottrell based method described above). The quantity $H_{m} p$ was subsequently subtracted from the experimentally determined drag stress and the saturation value, $Q_{m}$, identified. Equation 3.6 can be rearranged (as shown in equation 3.14 below) to find $b_{m}$ (note that values for $R_{m}$ and $p$ were chosen at the transitional "knee" point in the experimental drag stress profile).

$$
b_{m}=-\left(\ln \left(1-\frac{R_{m}}{Q_{m}}\right) / p\right)
$$

\subsubsection{Kinematic Hardening Parameters}

The monotonic loading region (first tensile branch) from thermally stable cyclic plasticity tests (specimens $160^{\circ} \mathrm{C}-400 \mathrm{~h}$ and $200^{\circ} \mathrm{C}-400 \mathrm{~h}$ ) was used to determine the kinematic hardening parameters. In doing this, it is assumed that all hardening is due to kinematic effects.

In cyclic plasticity testing, back stress components $\left(\chi_{1}\right.$ and $\left.\chi_{2}\right)$ a assumed to become dominant when the specimens exceed their elastic limit, as shown in figure 3.1. It was assumed that back stresses were dominant over certain plastic strain regions, such that $\chi_{2}$ had negligible influence in the $\chi_{1}$ dominant region, allowing the back stress to be calculated using equation 3.15. As the plastic strain increases, $\chi_{1}$ approaches saturation and $\chi_{2}$ becomes more dominant. This allows $\chi_{2}$ to be calculated using equation 3.16. Back stress may be plotted against the plastic strain from which $a_{1}, C_{1}, a_{2}$ and $C_{2}$ can be approximated. Note that $a_{1}$ is the saturated value of $\chi_{1}$ and $C_{1}$ was obtained in a similar way to $b_{m}$, where the chosen value for $\chi_{1}$ and $\varepsilon_{p}$ was taken at a transitional point on the $\chi_{1}$ curve. Values for $\chi_{1}$ and $p$ were substituted into equation 3.10 and rearranged to form equation 3.17. For this case, the accumulated plastic strain, $p$, was equal to the plastic strain of the monotonic curve. Once the parameters for $\chi_{1}$ were found, the same process was repeated to find the parameters $a_{2}$ and $C_{2}$ by substituting $\chi_{1}$ into equation 3.16 . 


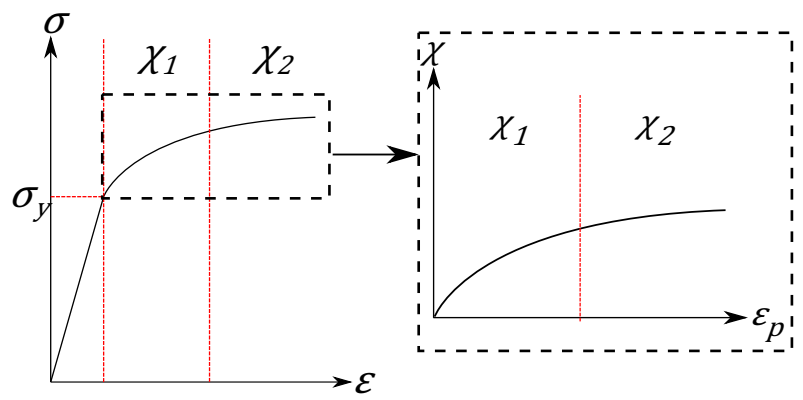

Figure 3.1: A schematic representation of how the monotonic curve was partitioned and the data used to determine the material constants for the back stresses $\chi_{1}$ and $\chi_{2}$.

$$
\begin{gathered}
\chi_{1}=\sigma-\sigma_{y} \\
\chi_{2}=\sigma-\sigma_{y}-\chi_{1} \\
C_{i}=-\left(\ln \left(1-\frac{X_{i}}{a_{i}}\right) / p\right)
\end{gathered}
$$

\subsubsection{Viscous Stress Parameters}

The results of stress relaxation tests (for samples soaked for 400 hours at $160^{\circ} \mathrm{C}$ and $200^{\circ} \mathrm{C}$ ) were used to obtain the viscous parameters $Z$ and $n$. Taking the logarithm of equation 3.12 gives equation 3.18. By plotting $\log (\dot{p})$ versus $\log \left(\sigma_{v}\right), n$ can be obtained from the gradient of the line of best fit and $Z$ from the y axis intercept. An exponential curve of best fit was used to approximate the data to avoid positive strain rates (due to scatter).

$$
\log \left(\sigma_{v}\right)=\frac{1}{n} \log (\dot{p})+\log (Z)
$$

The total strain rate can be described by equation 3.19 , where $\dot{\varepsilon}=0$ during the stress relaxation period. The quantities $\dot{p}=-\frac{\dot{\sigma}}{E}$ and $\dot{\sigma}$ (stress rate) were calculated using a backwards difference method (see equation 3.20). Viscous stress may be approximated using equation 3.21.

$$
\begin{gathered}
\dot{\varepsilon}=\dot{p}+\frac{\dot{\sigma}}{E} \\
\dot{\sigma}=\frac{\sigma_{i}-\sigma_{i-1}}{t_{i}-t_{i-1}} \\
\sigma_{v}=\sigma-R-\chi_{1}-\chi_{2}-k
\end{gathered}
$$

\subsubsection{Material Ageing Parameters}

Once the material constants for the fully-aged samples have been established the parameters that describe ageing may be estimated. In a fully aged material the yield locus size prior to the accumulation is assumed to be equivalent to the initial cyclic yield stress of the material $(k)$. It can be reasoned that, to describe the material's yield strength as a function of time at temperature, a scalar stress value $\left(R_{a}\right)$ must be added to $k$ that decays with time.Furthermore, $R_{a}$ must decay to a value of 0 to accurately predict the stress data of the fully-aged samples. To determine $R_{a}, k$ was subtracted from the radius of the yield 
surface of each tensile branch in cyclic plasticity test results (samples in these cases had no prior ageing), equivalent to $\frac{\sigma_{e l}}{2}$ (see equation 3.22). Associated exposure times were estimated as the total test time at the beginning of the cycle. Equation 3.8 was fitted to $R_{a}$ versus time plots in order to approximate the constants $Q_{a 1}, Q_{a 2}, b_{a 1}$ and $b_{a 2}$.

$$
R_{a}=\frac{\sigma_{e l}}{2}-k
$$

\section{Predictive Model Results}

Using the methods described in the previous section a set of initial material parameter estimates can be developed and fine tuned (optimised) by defining a stress based objective function (which utilises experimental data). In the present work, material parameters relating to mechanical hardening are determined by optimising the relevant constants against fully aged (400 hour exposure with no prior mechanical strain) test results. With these determined, ageing material parameters may be optimised against as received cyclic plasticity results (i.e. no prior exposure to elevated temperature). It must be noted that, during this secondary optimisation procedure, parameters relating to mechanical hardening are fixed. What is now presented is a selection of comparison plots (comparing numerical estimated responses to experimental results) that demonstrate the predictive capability of the developed model. Two isothermal test conditions are considered (namely $160^{\circ} \mathrm{C}$ and $200^{\circ} \mathrm{C}$ ) and samples have a variety of prior ageing histories (see section 2.3). In this section, the coefficient of determination $\left(r^{2}\right)$, error in the maximum stress $\left(e_{\sigma_{\max }}\right)$, and the error in plastic strain range $\left(e_{\Delta \varepsilon_{p}}\right)$ are used as metric by which to judge the predictive capability of the developed model.

\subsection{Stress Prediction of the "Fully-Aged" Specimens}

Figures 4.1 and 4.2 show the experimental stress amplitude and the stress-strain hysteresis loops for cycles 1, 1000 and 2000, and the predicted stress values using the initial and optimised materials constants for the samples $160^{\circ} \mathrm{C}-400 \mathrm{~h}$ and $200^{\circ} \mathrm{C}-400 \mathrm{~h}$, respectively. It can be seen that there is a strong agreement between the experimental data and the model prediction in both conditions. Table 4.1 presents the initial and optimised constants for samples $160^{\circ} \mathrm{C}-400 \mathrm{~h}$ and $200^{\circ} \mathrm{C}-400 \mathrm{~h}$. Relatively large differences are observed between initial and optimisation material responses in figures 4.1 and 4.2 . From table 4.1 it can be seen that the main difference between initial and optimised material parameters relates to the parameter $b_{m}$. Optimisation looks to fine tune the saturation of the first (nonlinear) mechanical isotropic term. A largely elastic response is predicted by the initial material parameter set as the initial yield surface size $(k)$ is relatively large (in order to agree with monotonic test results). 


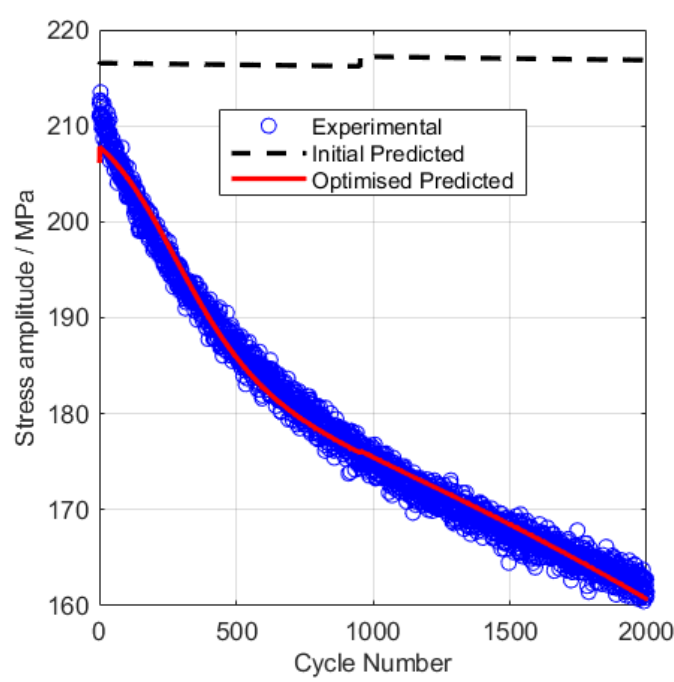

(a)

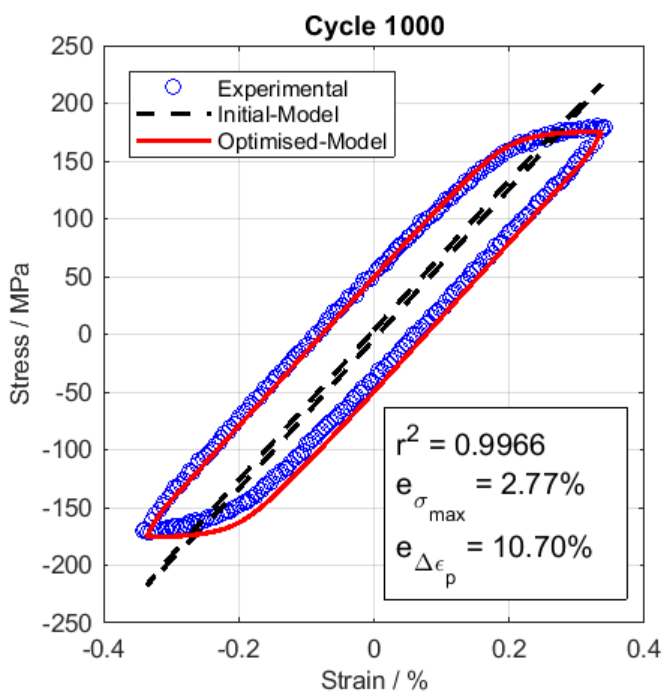

(c)

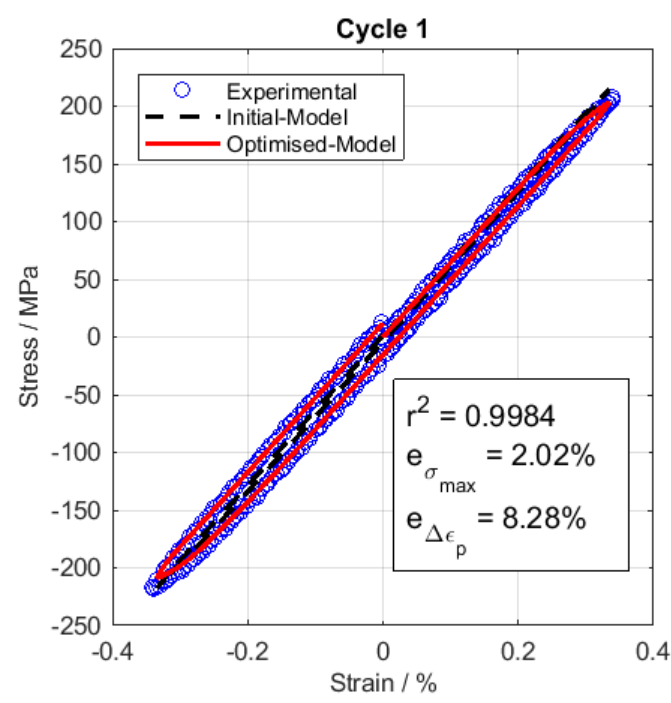

(b)

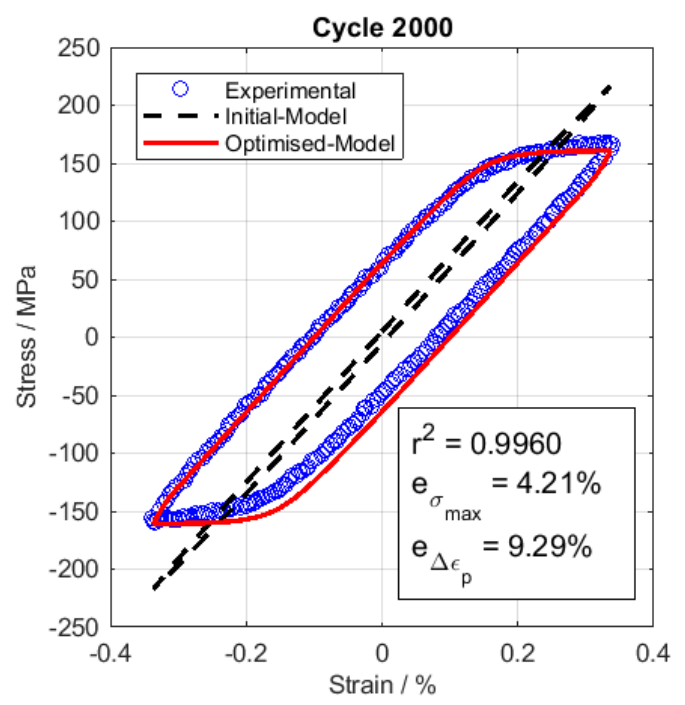

(d)

Figure 4.1: Predicted stress for specimen $160^{\circ} \mathrm{C}-400 \mathrm{~h}$, demonstrating (a) the cycle softening behaviour and the hysteresis loops of (b) cycle 1, (c) cycle 1000 and (d) cycle 2000. 


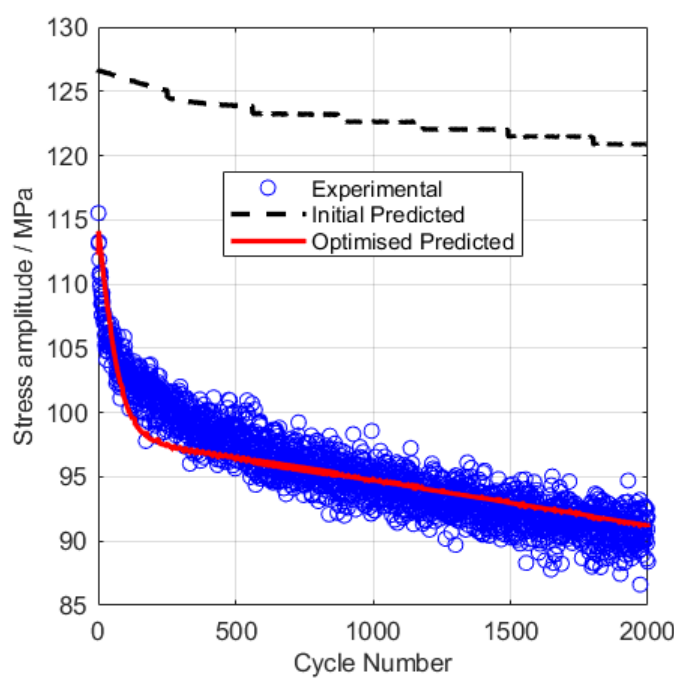

(a)

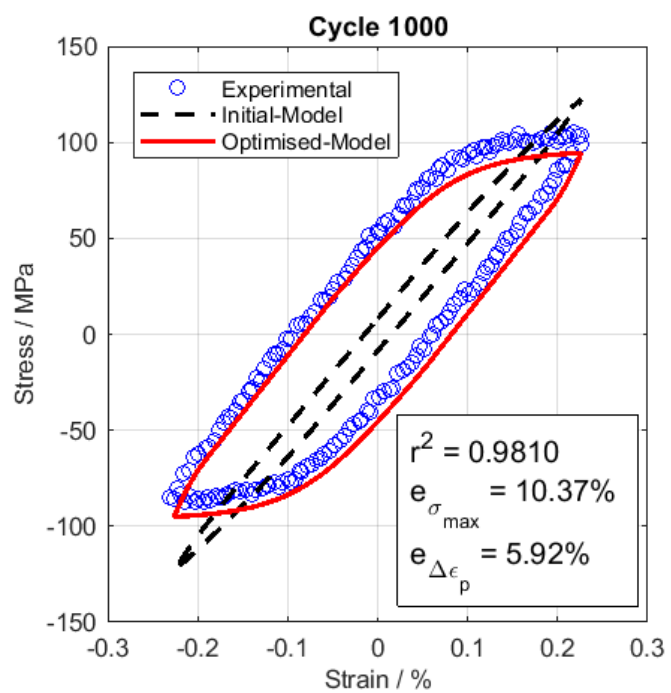

(c)

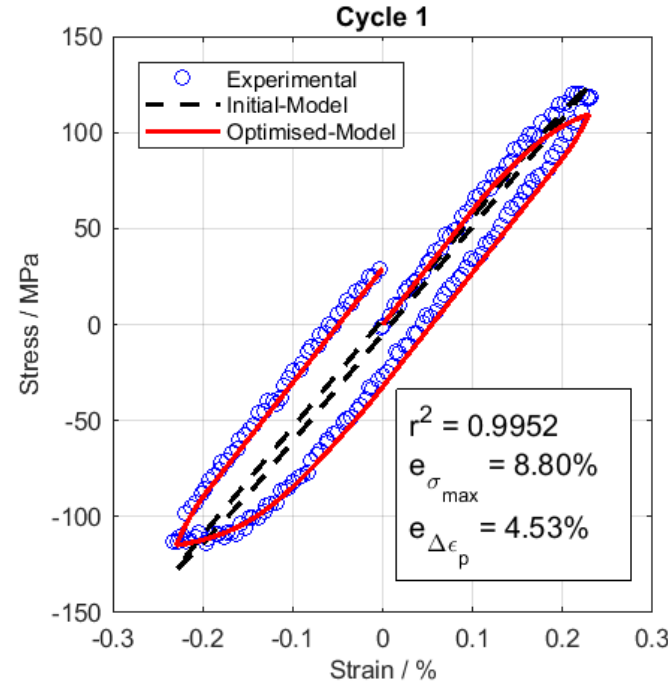

(b)

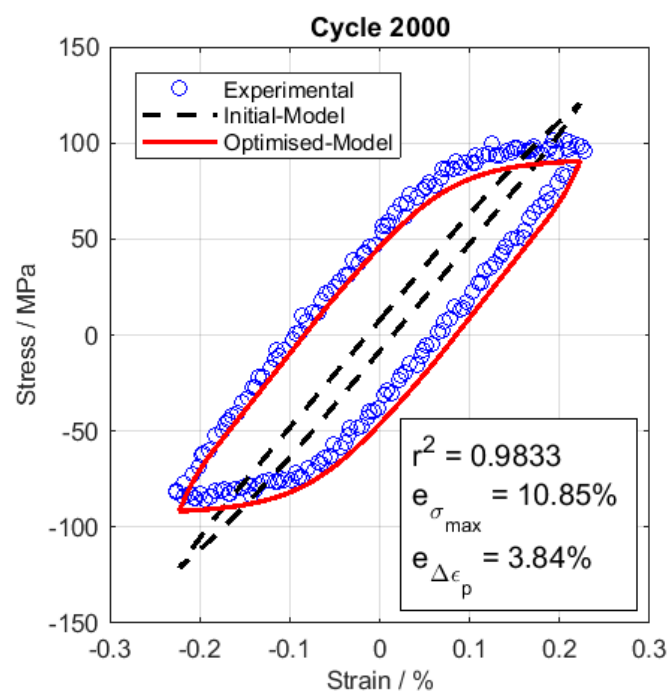

(d)

Figure 4.2: Predicted stress for specimen $200^{\circ} \mathrm{C}-400 \mathrm{~h}$, demonstrating (a) the cycle softening behaviour and the hysteresis loops of (b) cycle 1, (c) cycle 1000 and (d) cycle 2000. 
Table 4.1: A table of the initial and optimised material constants for the $160^{\circ} \mathrm{C}-400 \mathrm{~h}$ and $200^{\circ} \mathrm{C}-400 \mathrm{~h}$ specimens.

\begin{tabular}{ccccc}
\hline & \multicolumn{2}{c}{$160^{\circ} \mathrm{C}$} & \multicolumn{2}{c}{$200^{\circ} \mathrm{C}$} \\
Material Parameters & Initial & Optimised & Initial & Optimised \\
\hline$a_{1}(\mathrm{MPa})$ & 13.31 & 19 & 14.71 & 18.19 \\
$C_{1}$ & 52810 & 30539 & 18514 & 16283 \\
$a_{2}(\mathrm{MPa})$ & 14.33 & 22.19 & 6.14 & 6.43 \\
$C_{2}$ & 16541 & 19982 & 5246 & 5690 \\
$Z\left(\mathrm{MPa} \cdot \mathrm{s}^{1 / n}\right)$ & 235660 & 91417 & 543820 & 564700 \\
$n$ & 1.48 & 1.25 & 1.17 & 1.01 \\
$Q_{m}(\mathrm{MPa})$ & -37.1 & -32.34 & -23.32 & -19.26 \\
$b_{m}$ & 1.92 & 2.23 & 13.79 & 6.89 \\
$H_{m}(\mathrm{MPa})$ & -4.19 & -4.19 & -0.94 & -0.94 \\
$Q_{a 1}$ & 0 & 0 & 0 & 0 \\
$b_{a 1}$ & 0 & 0 & 0 & 0 \\
$Q_{a 2}$ & 0 & 0 & 0 & 0 \\
$b_{a 2}$ & 0 & 0 & 0 & 0 \\
$k(\mathrm{MPa})$ & 145 & 146 & 89 & 63 \\
$E(\mathrm{MPa})$ & 65000 & 64501 & 56000 & 59499 \\
\hline & & & &
\end{tabular}

\subsection{Stress Prediction of the As-Received Specimens}

Figures 4.3 and 4.4 show the experimental stress amplitude and a several selected cycles (specified in the figures) compared to the model predicted numerical values before and after the material ageing parameters were optimised for samples $160^{\circ} \mathrm{C}-0 \mathrm{~h}$ and $200^{\circ} \mathrm{C}-0 \mathrm{~h}$, respectively.

Figures 4.3 and 4.4 again show a strong correlation between the experimental and model predicted response, both in terms of the material softening and hysteresis loops at various cycle numbers, for both temperature conditions.

Table 4.2 shows the initial and the complete set of material constants for the Chaboche model of the 7175-T7351 aluminium alloy at $160^{\circ} \mathrm{C}$ and $200^{\circ} \mathrm{C}$. 


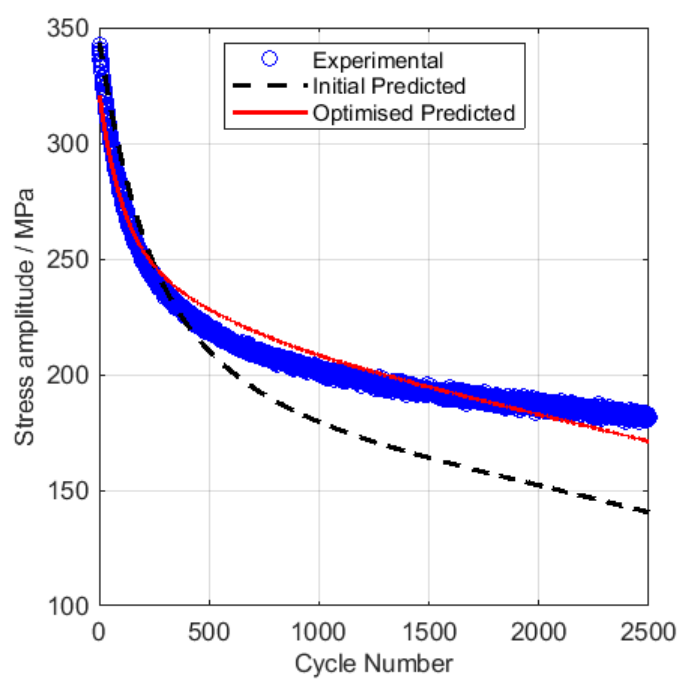

(a)

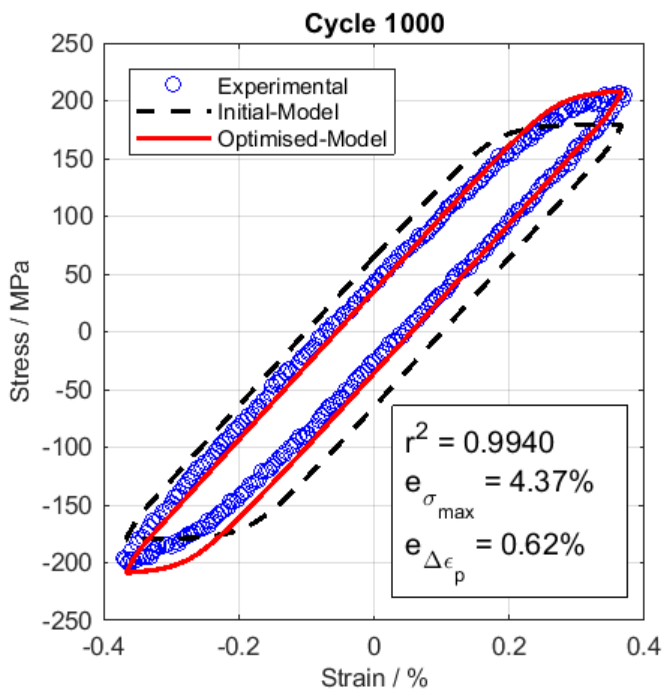

(c)

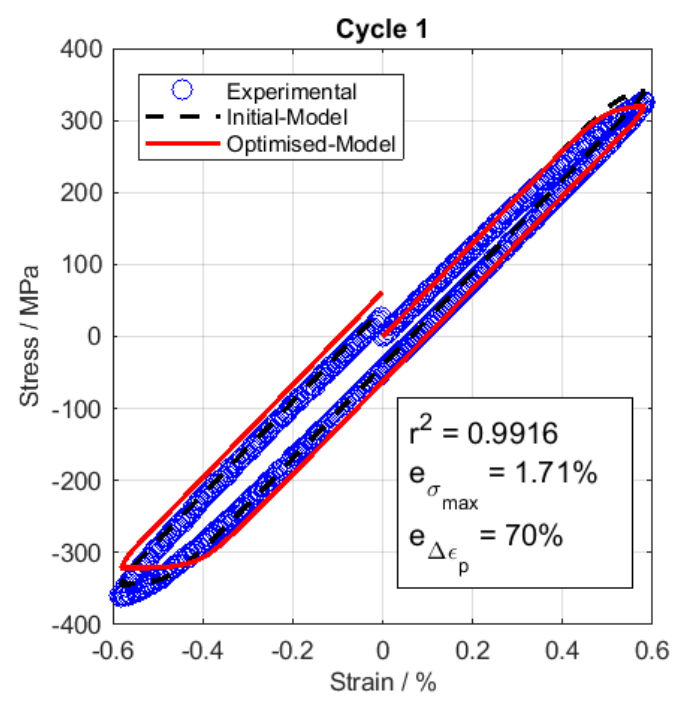

(b)

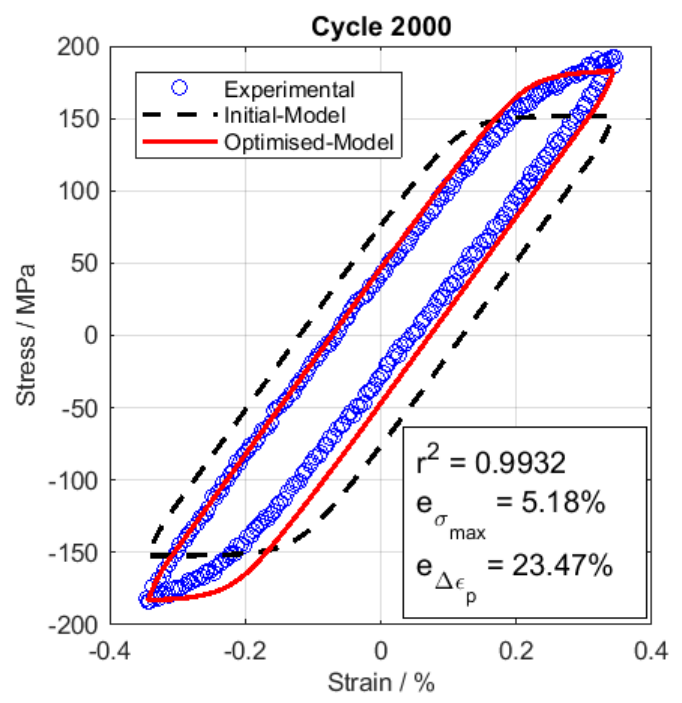

(d)

Figure 4.3: Predicted stress for specimen $160^{\circ} \mathrm{C}-0 \mathrm{~h}$, demonstrating (a) the cycle softening behaviour and the hysteresis loops of (b) cycle 1, (c) cycle 1000 and (d) cycle 2000. 


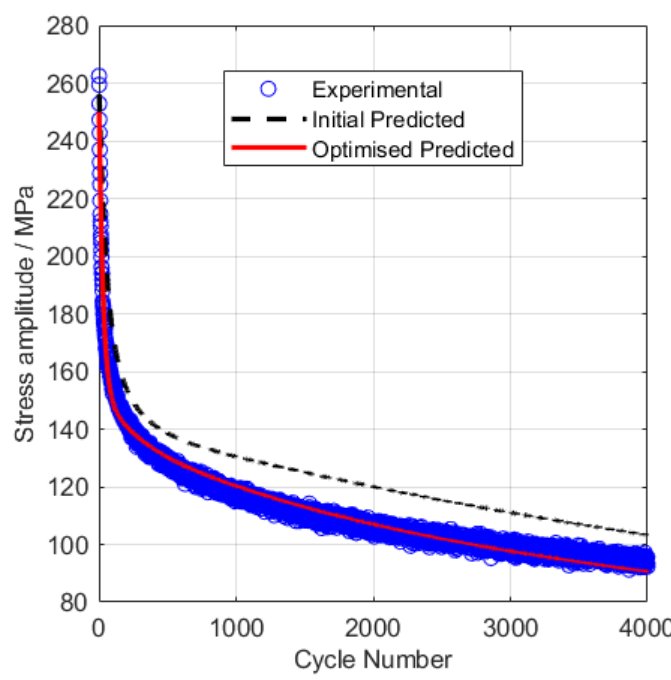

(a)

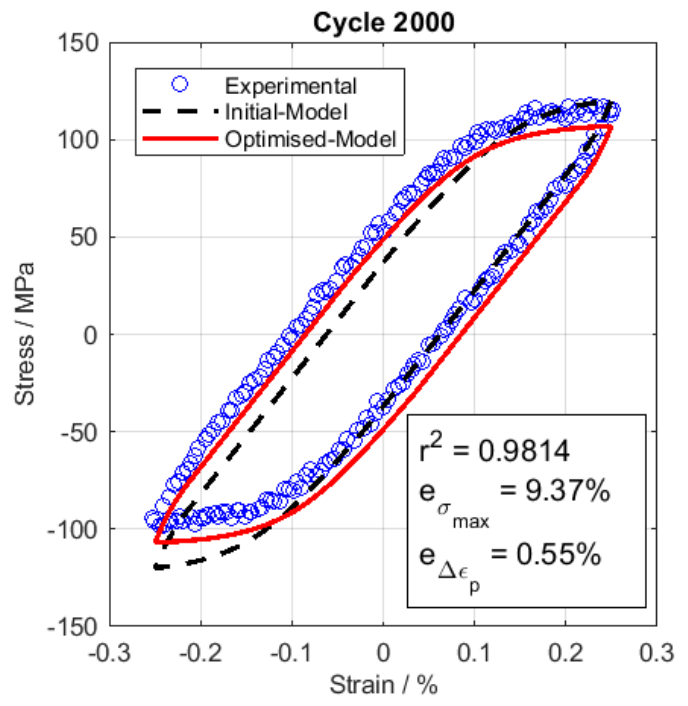

(c)

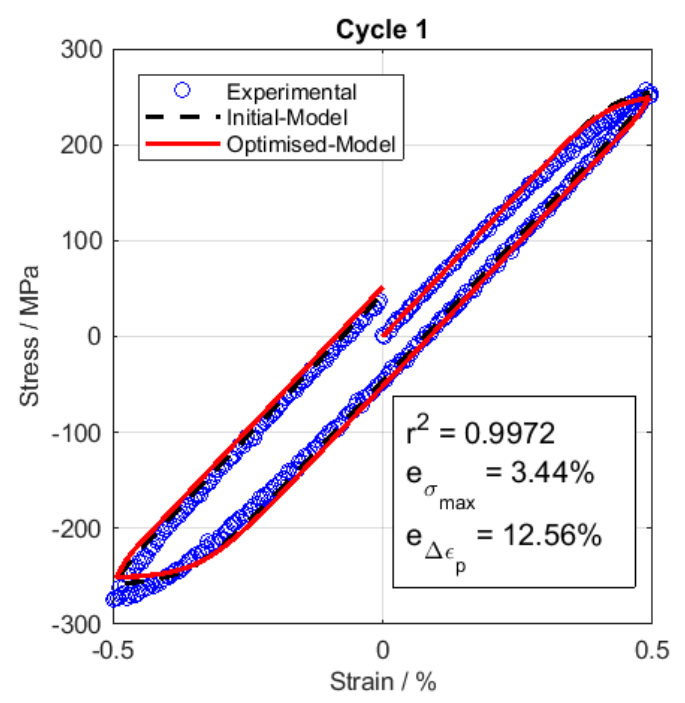

(b)

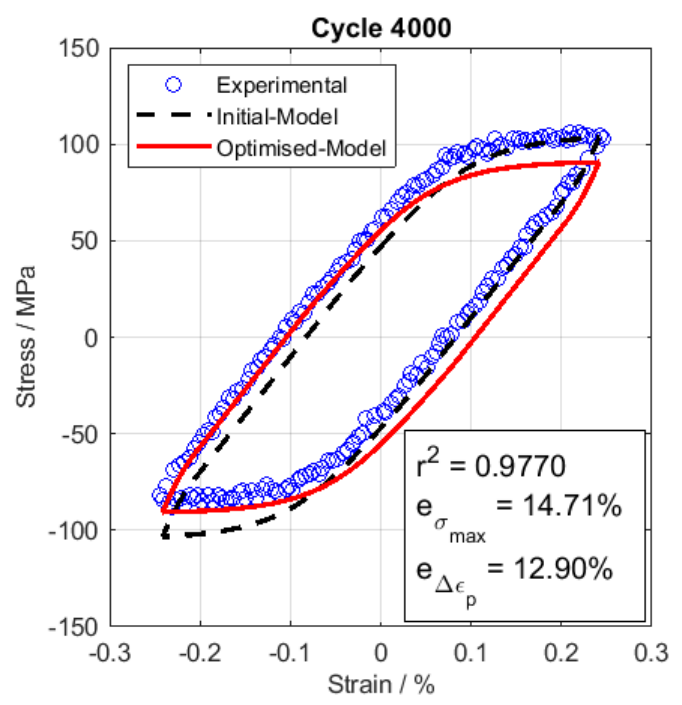

(d)

Figure 4.4: Predicted stress for specimen $200^{\circ} \mathrm{C}-0 \mathrm{~h}$, demonstrating (a) the cycle softening behaviour and the hysteresis loops of (b) cycle 1, (c) cycle 2000 and (d) cycle 4000.

As mentioned previously, the isotropic softening due to material ageing, $R_{a}$, should asymptotically approach $0 M P a$, assuming that a material reaches a thermally stable or fully aged state (in the case of aluminium 7175-T7351 this state appears to be achieved after 400 hours of exposure at elevated temperature). It may be shown that, after 400 hours of exposure, the predictive model developed in the present work suggests a value for $R_{a}$ of $0.77 \mathrm{MPa}$ and $5.37 \mathrm{MPa}$ for the $200^{\circ} \mathrm{C}$ and $160^{\circ} \mathrm{C}$ test/soak temperature conditions, respectively. Given that total ageing stress contributions are approximately $100 M P a$, this level of decay is deemed to be acceptable. 
Table 4.2: A table of the initial and optimised set of material constants for the $160^{\circ} \mathrm{C}-0 \mathrm{~h}$ and $200^{\circ} \mathrm{C}-0 \mathrm{~h}$ specimen.

\begin{tabular}{ccccc}
\hline & \multicolumn{2}{c}{160} & \multicolumn{2}{c}{200} \\
Material Parameters & Initial & Optimised & Initial & Optimised \\
\hline$a_{1}(\mathrm{MPa})$ & 19 & 19 & 18.19 & 18.19 \\
$C_{1}$ & 30539 & 30539 & 16283 & 16283 \\
$a_{2}(\mathrm{Mpa})$ & 22.19 & 22.19 & 6.43 & 6.43 \\
$C_{2}$ & 19982 & 19982 & 5690 & 5690 \\
$Z\left(\mathrm{MPa} . \mathrm{s}^{1 / n}\right)$ & 91417 & 91417 & 564700 & 564700 \\
$n$ & 1.25 & 1.25 & 1.01 & 1.01 \\
$Q_{m}(\mathrm{MPa})$ & -32.34 & -32.34 & -19.26 & -19.26 \\
$b_{m}$ & 2.23 & 2.23 & 6.89 & 6.89 \\
$H_{m}(\mathrm{MPa})$ & -4.19 & -4.19 & -0.94 & -0.94 \\
$Q_{a 1}(\mathrm{MPa})$ & 128.3 & 74 & 86.91 & 84.58 \\
$b_{a 1}$ & $-6.67 \mathrm{E}-06$ & $-1.82 \mathrm{E}-05$ & $-4.07 \mathrm{E}-05$ & $-8.90 \mathrm{E}-05$ \\
$Q_{a 2}(\mathrm{MPa})$ & 0 & 30.71 & 54.51 & 50.89 \\
$b_{a 2}$ & $-6.67 \mathrm{E}-06$ & $-2.01 \mathrm{E}-05$ & $-1.59 \mathrm{E}-06$ & $-2.91 \mathrm{E}-06$ \\
$k(\mathrm{MPa})$ & 146 & 146 & 63 & 63 \\
$E(\mathrm{MPa})$ & 64501 & 64501 & 59499 & 59499 \\
\hline
\end{tabular}

\subsection{Chaboche Model Validation - Stress Prediction of "Partially-Aged" and "Fully-Aged" Samples}

The ageing term enhanced unified elastic viscoplastic model described in the present work is used here to predict the isothermal fatigue stress data of the "partially-aged" samples (designated $160^{\circ} \mathrm{C}-100 \mathrm{~h}$ and $200^{\circ} \mathrm{C}-75 \mathrm{~h}$ ). This was done in order to verify the material parameters determined through the sequential optimisation procedure described above. Figures 4.5 and 4.6 show the predicted response for samples $160^{\circ} \mathrm{C}-100 \mathrm{~h}$ and $160^{\circ} \mathrm{C}-400 \mathrm{~h}$. For both cases, the model slightly over-estimated the stress amplitude. The prediction of the hysteresis loops in figures $4.5 \mathrm{~b}$ to $4.5 \mathrm{~d}$ show that the yielding occurs at a greater stress than expected.

Figure 4.7 shows that the material constants obtained for $200^{\circ} \mathrm{C}$ provide a good approximation of the material response of the $200^{\circ} \mathrm{C}-75 \mathrm{~h}$ sample. Both the errors in plastic strain range and maximum stress are below $12 \%$.

Figure 4.8 shows that when the material constants for $200^{\circ} \mathrm{C}$ were used to the predict the material response of the $200^{\circ} \mathrm{C}-400 \mathrm{~h}$ sample, the results were still in good agreement. Both the errors in plastic strain range and maximum stress remained below $10 \%$. 


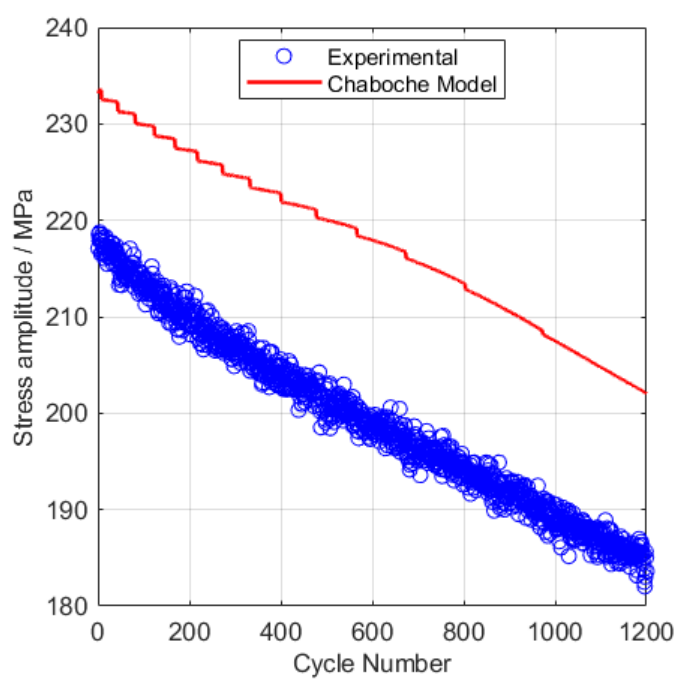

(a)

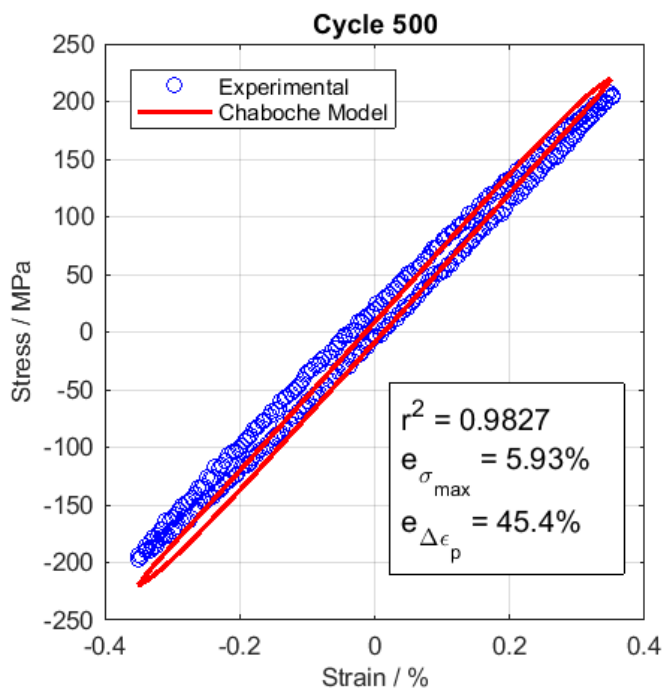

(c)

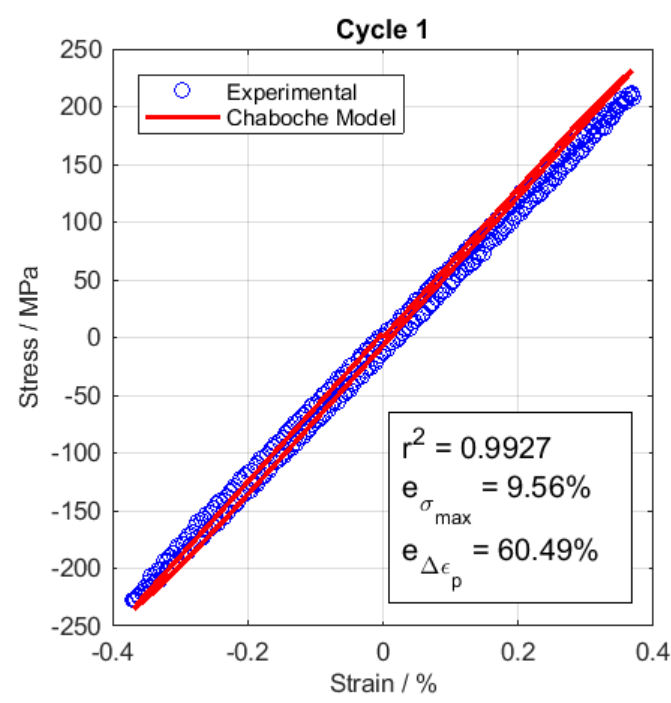

(b)

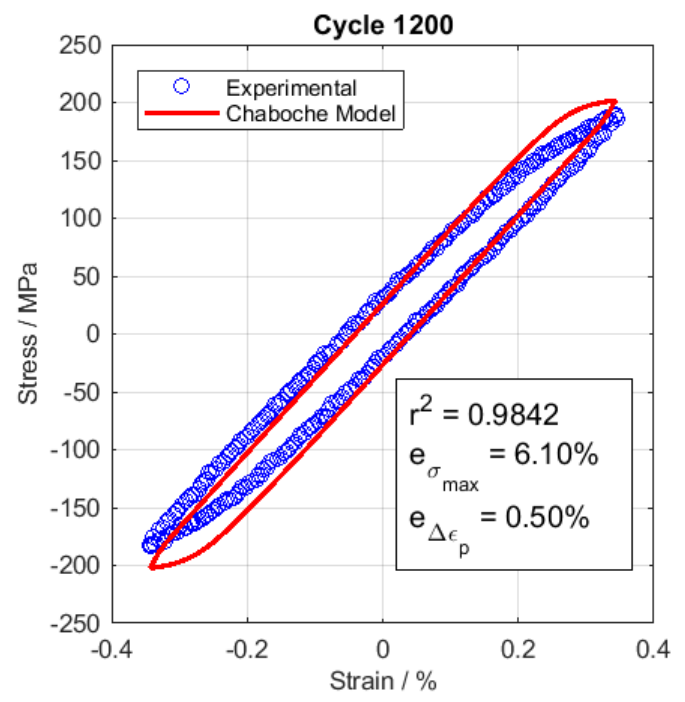

(d)

Figure 4.5: Predicted stress for specimen $160^{\circ} \mathrm{C}-100 \mathrm{~h}$, demonstrating (a) the cycle softening behaviour and the hysteresis loops of (b) cycle 1, (c) cycle 1000 and (d) cycle 1200. 


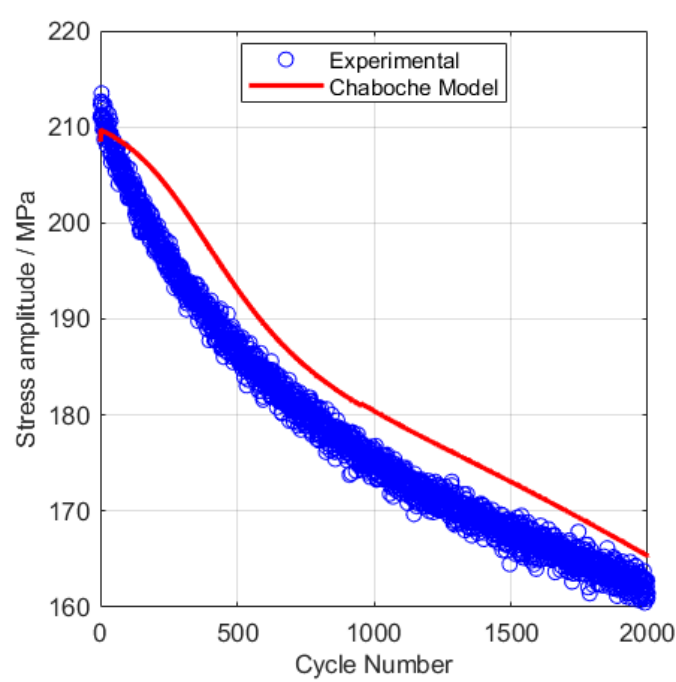

(a)

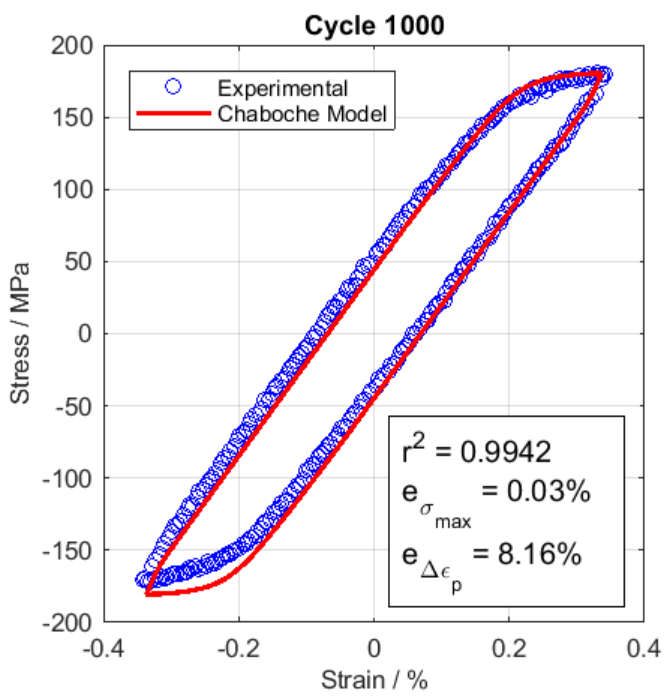

(c)

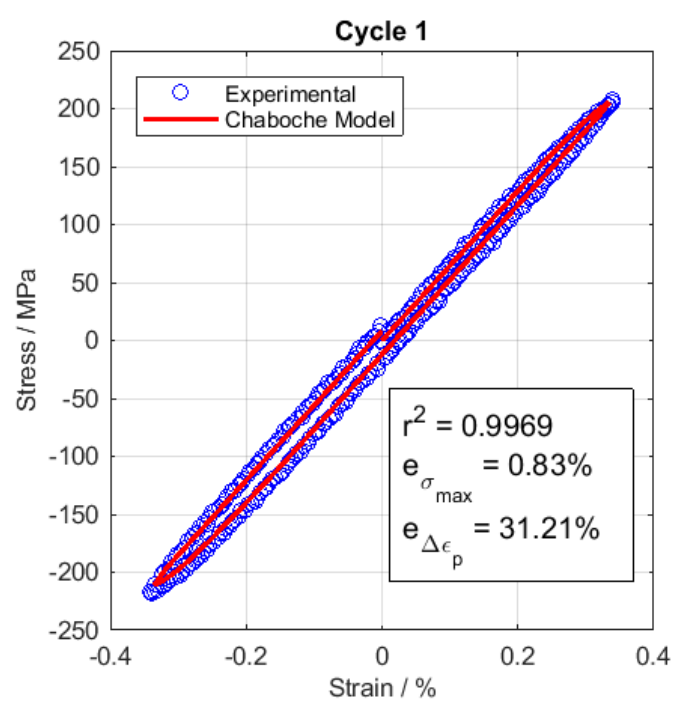

(b)

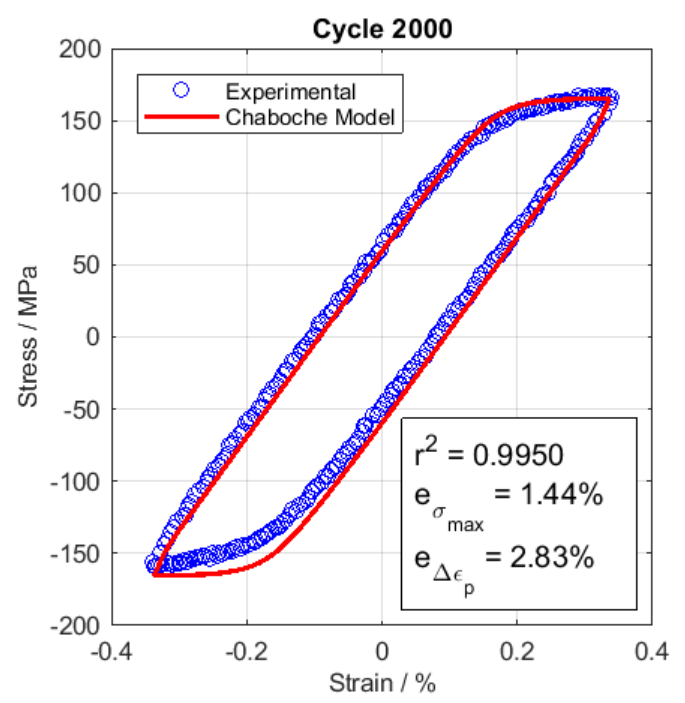

(d)

Figure 4.6: Prediction for the sample $160^{\circ} \mathrm{C}-400 \mathrm{~h}$ using the complete set of material constants at $160^{\circ} \mathrm{C}$. (a) Cycle softening behaviour and the hysteresis loops of (b) cycle 1, (c) cycle 1000 and (d) cycle 2000 . 


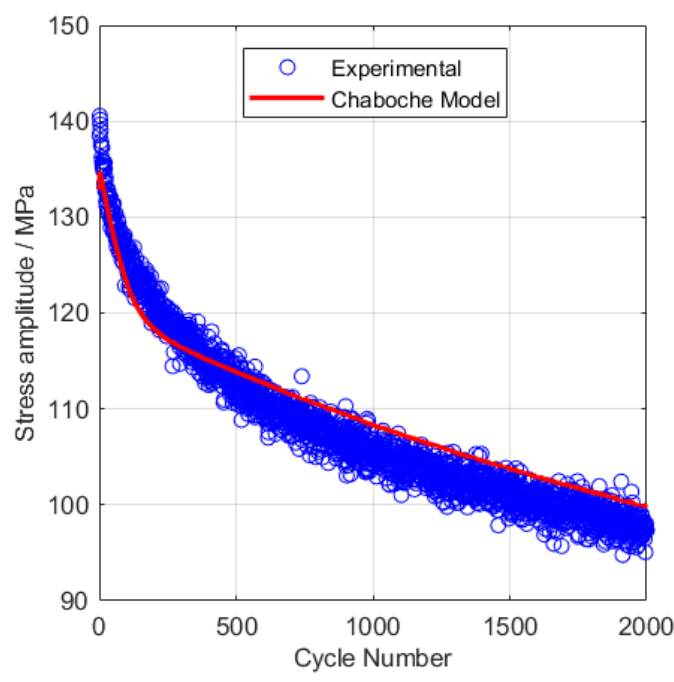

(a)

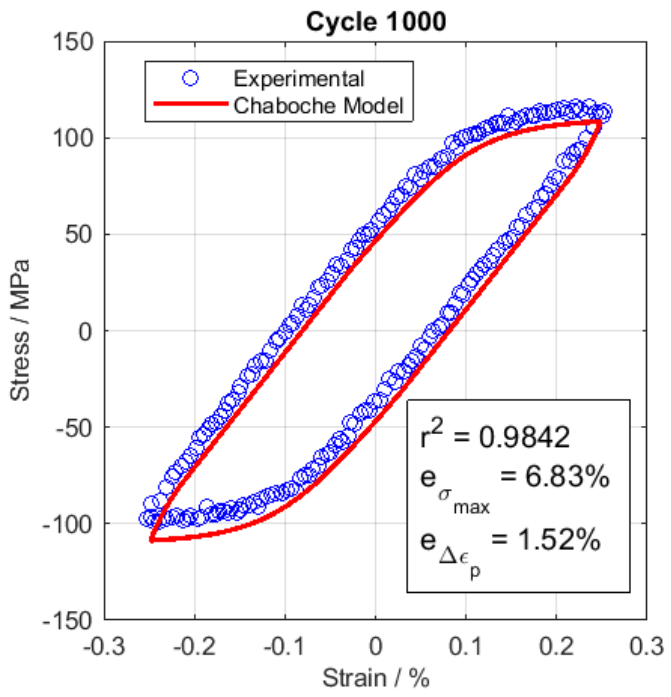

(c)

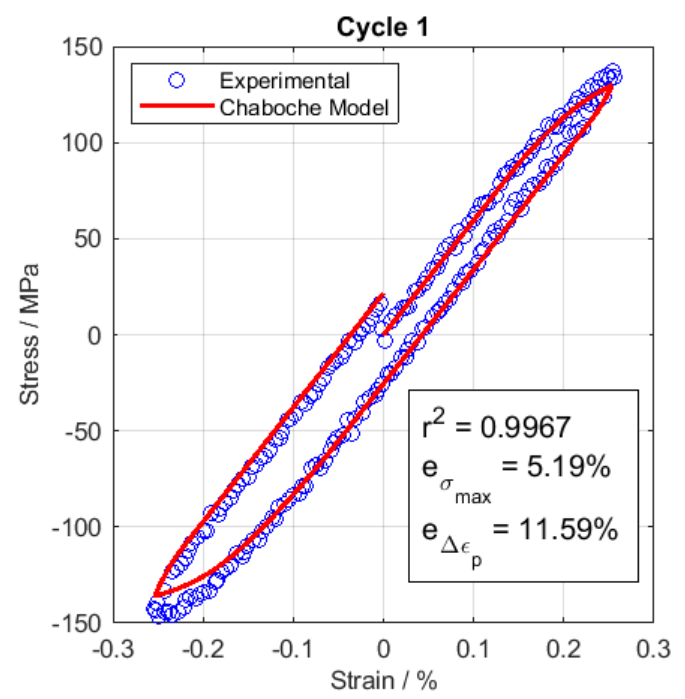

(b)

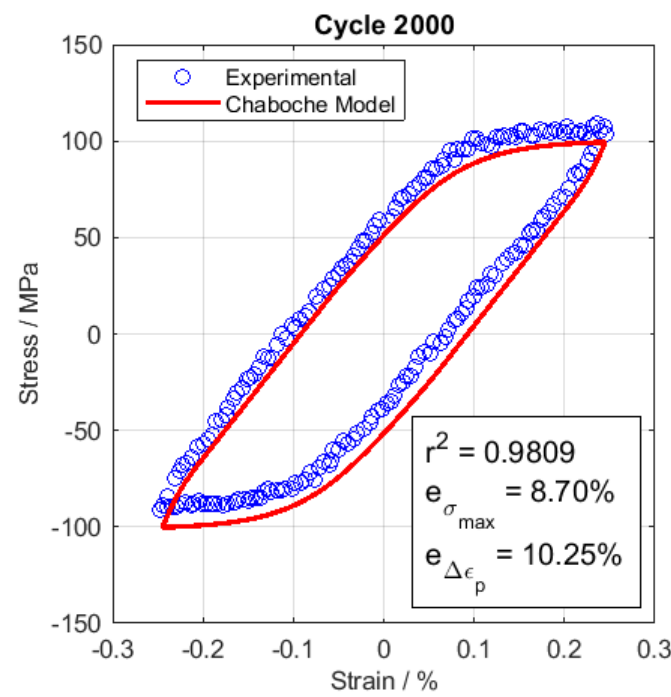

(d)

Figure 4.7: Prediction for the sample $200^{\circ} \mathrm{C}-75 \mathrm{~h}$ using the complete set of material constants at $200^{\circ} \mathrm{C}$. (a) Cycle softening behaviour and the hysteresis loops of (b) cycle 1, (c) cycle 1000 and (d) cycle 2000. 


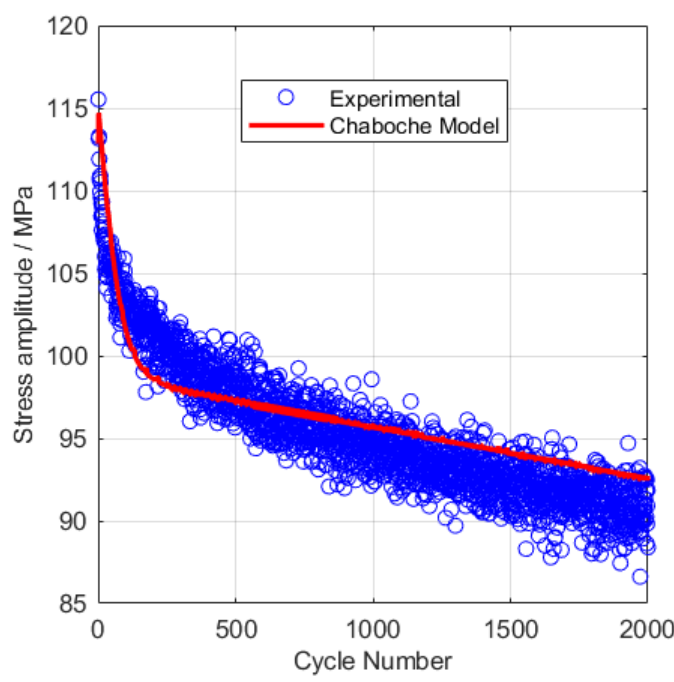

(a)

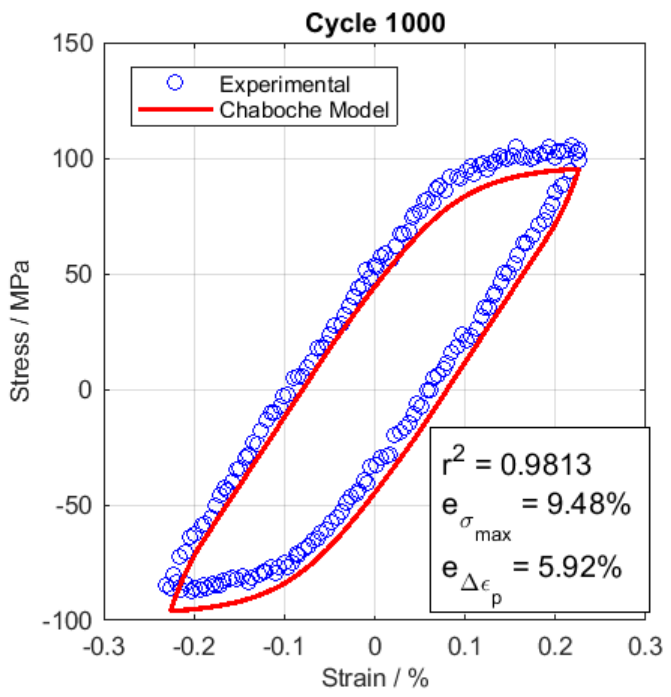

(c)

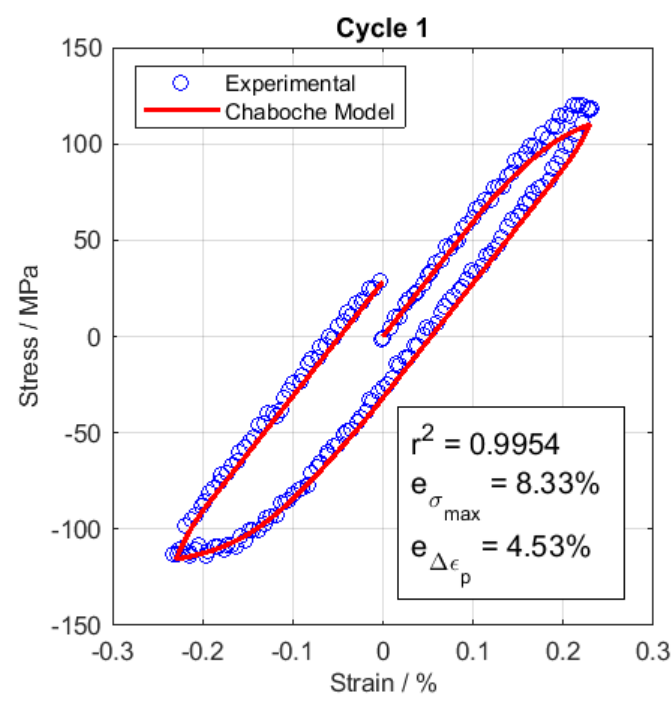

(b)

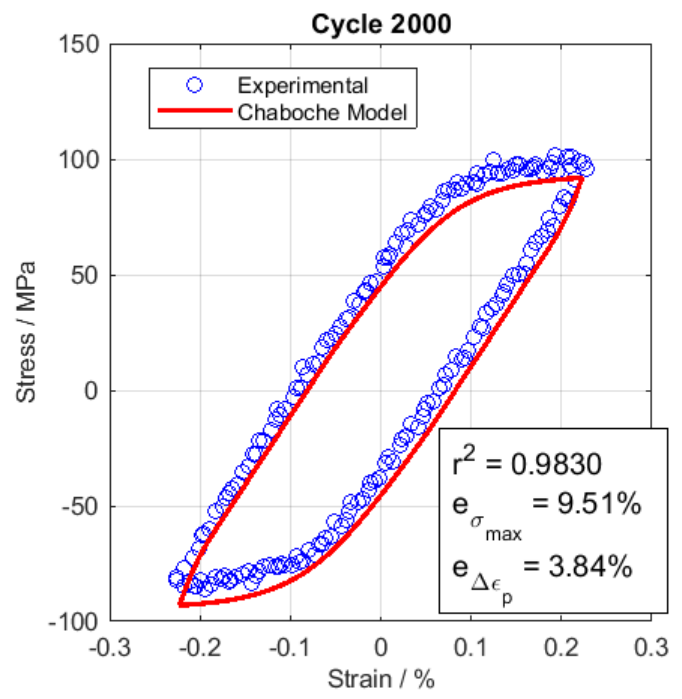

(d)

Figure 4.8: Prediction for the sample $200^{\circ} \mathrm{C}-400 \mathrm{~h}$ using the complete set of material constants at $200^{\circ} \mathrm{C}$. (a) Cycle softening behaviour and the hysteresis loops of (b) cycle 1, (c) cycle 1000 and (d) cycle 2000 .

\section{Microstructural Analysis and Observations on Ageing Phenomenon}

The microstructure of the 7175 aluminium alloy at various stages of ageing at $200^{\circ} \mathrm{C}$ (namely as-received, 24 hours, 75 hours and 400 hours) is analysed here in order to provide a physical underpinning for the ageing phenomenon described above in a phenomenological sense. A particular motivation for this exercise was the identification of the microstructural evolution features responsible for thermal ageing. Transmission electron microscopy (TEM) images of the as-received and soaked (at $200^{\circ} \mathrm{C}$ for 24 hours, 75 hours and 400 hours) material are presented in figure 5.1. Precipitates within the grains can clearly be seen and there appears to be correlation between size and spacing with exposure time (i.e. time at temperature), however partial identification through diffraction pattern matching initially proved difficult due to interference between the matrix material and the particles themselves. In order to 
suggest candidate precipitates, energy dispersive spectroscopy (EDS) was implemented on a scanning electron microscope (SEM), thereby producing an element map. An example SEM based element map (for 24 hour aged $200^{\circ} \mathrm{C}$ material) is presented in figure 5.2, with element maps of aluminium, zinc, magnesium, copper and chromium highlighted individually. Of particular note is the concentration of zinc and magnesium at dispersed particle locations.

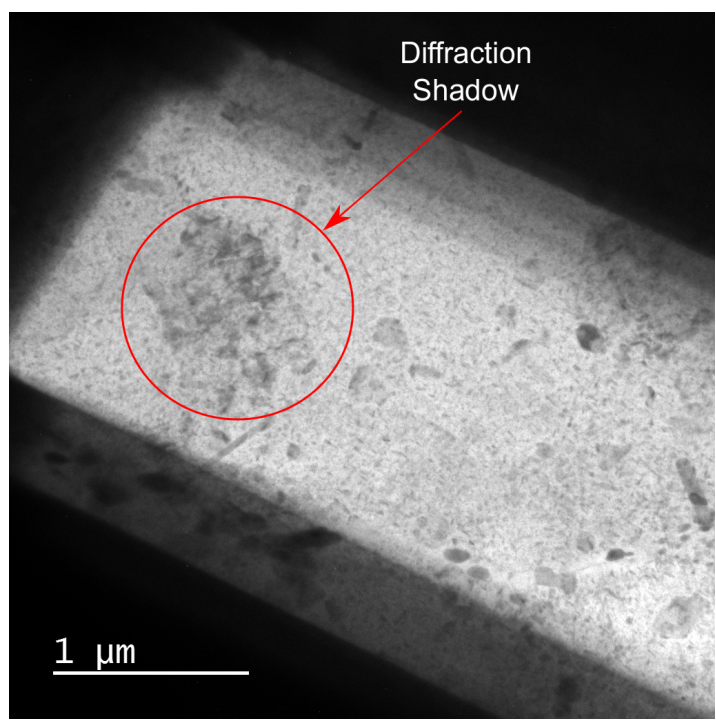

(a)

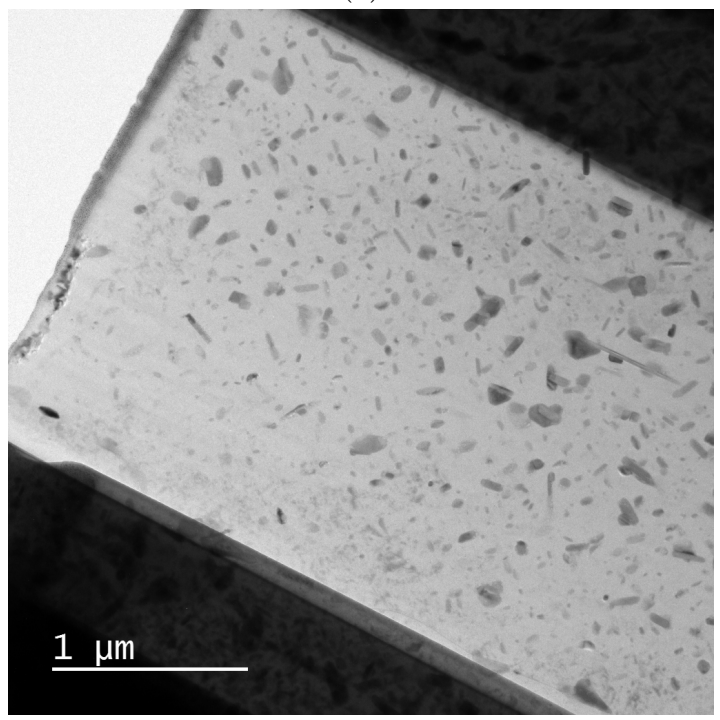

(c)

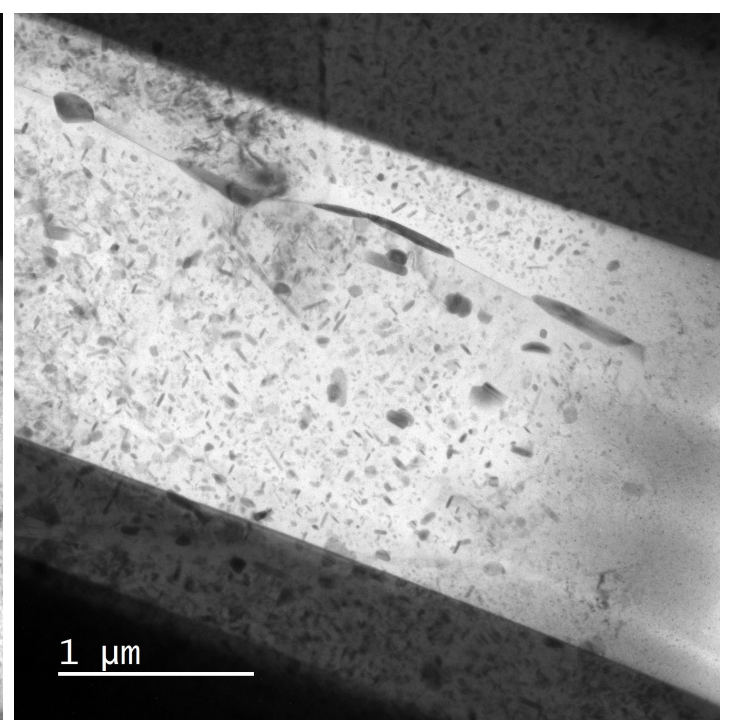

(b)

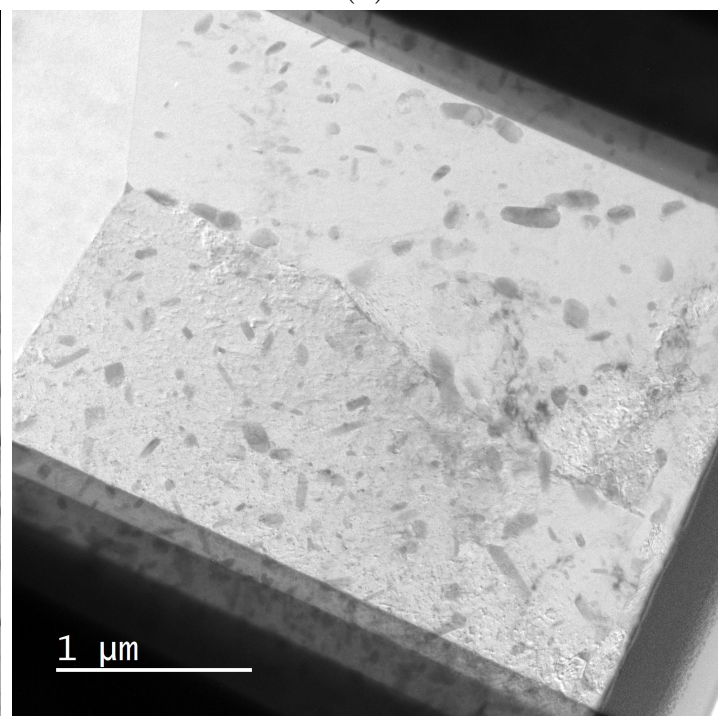

(d)

Figure 5.1: TEM images showing and overview (x6000 magnification) of the 7175-T7351

microstructure after soaking at $200^{\circ} \mathrm{C}$ for (a) 0 hours (as-received material), (b) 24 hours, (c) 75 hours and (d) 400 hours. 


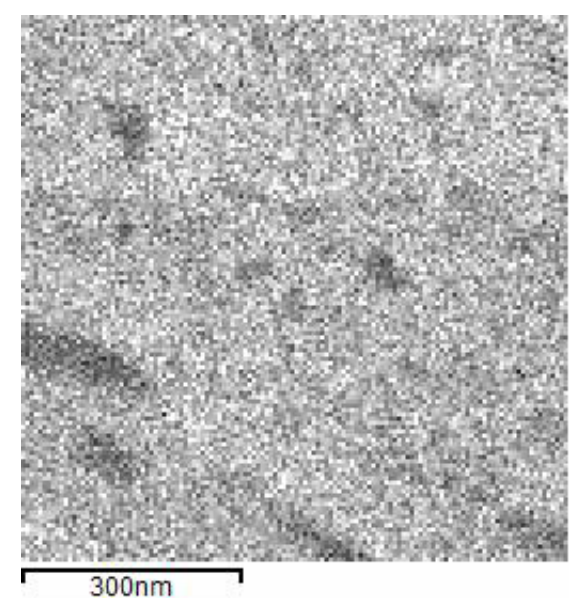

(a)

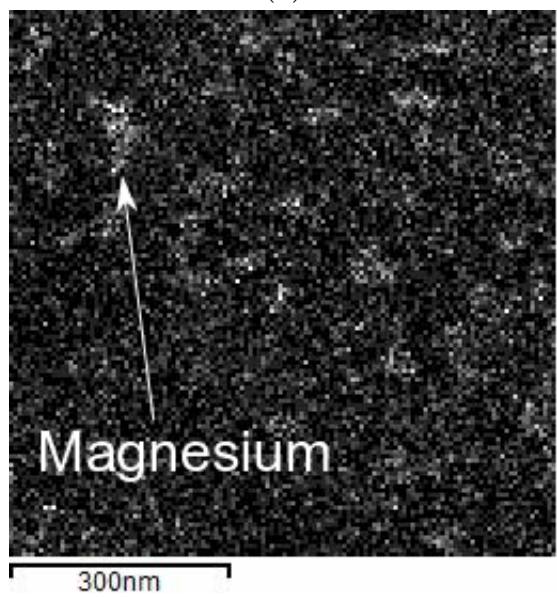

(c)

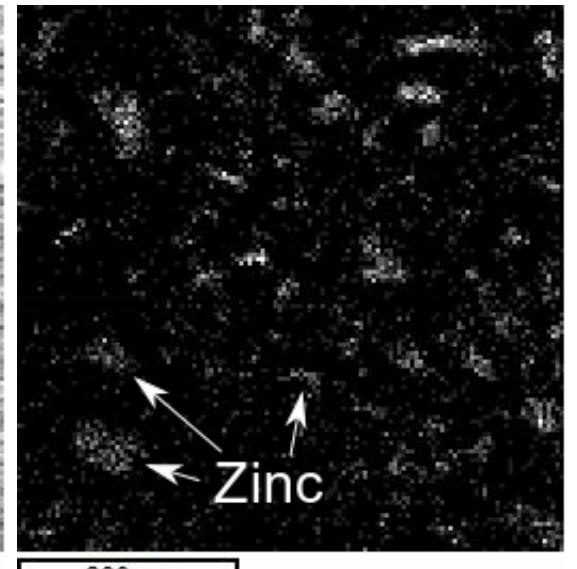

300nm

(b)

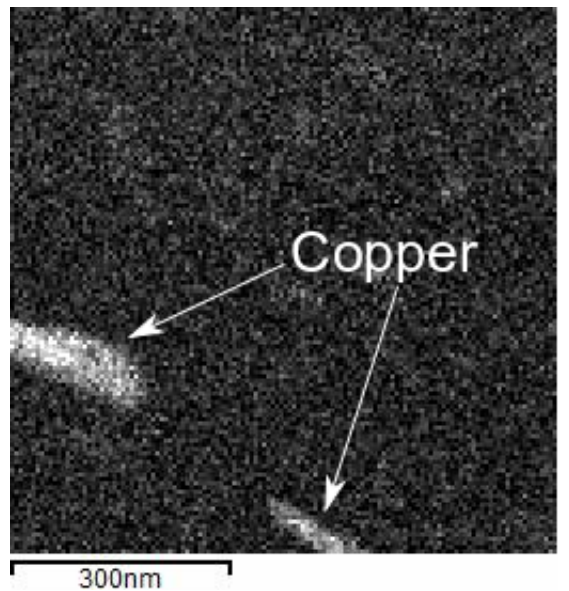

(d)

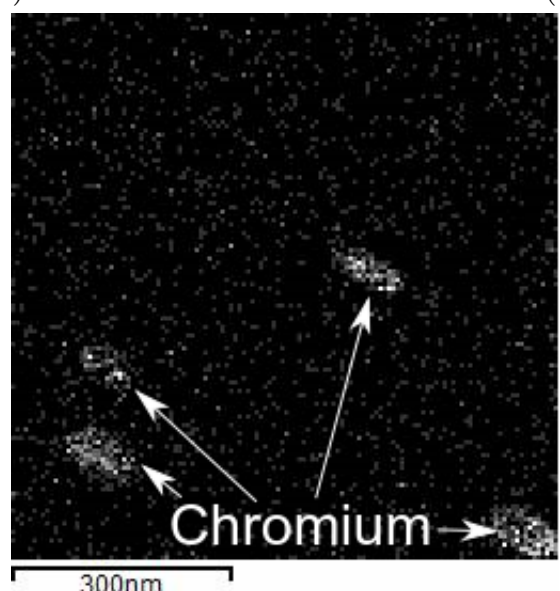

(e)

Figure 5.2: Element maps for the 24 hour soak $\left(200^{\circ} \mathrm{C}\right)$ material, showing concentrations of (a) aluminium, (b) zinc, (c) magnesium, (d) copper, and (d) chromium.

With element maps in hand, energy-dispersive X-ray spectroscopy could be performed using a TEM in order to determine the magnesium/zinc particle structure. 7 particles (s5, s6, s7, s8, s9, s10, and s11) are identified in figure 5.3 (a), with the diffraction pattern of particle s8 shown in figure 5.3 (b). Miller indices, lattice vectors and d-spacings were compared to data from the International Centre for Diffraction Data (ICDD) (Powder Dffraction File 00-034-0457), identifying the particles as hexagonal close packed $\mathrm{MgZn}_{2}$. The same method was used to identify other particles within the material. Figure 
5.4 shows a long dark particle lying on a grain boundary and its diffraction pattern. Using ICDD, this particle was identified as $\mathrm{Al}_{2} \mathrm{Cu}$ phase.

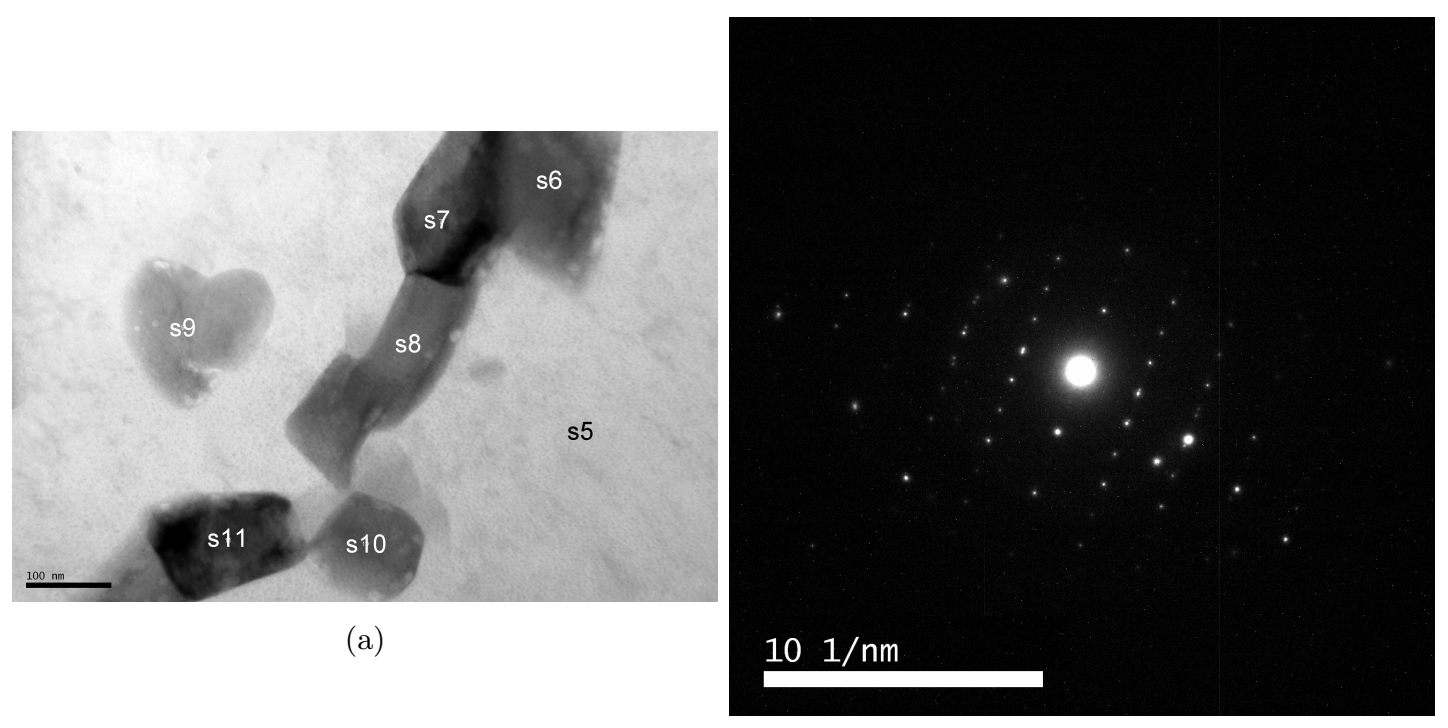

(b)

Figure 5.3: The results of TEM EDX, showing (a) analysed particles and (b) the diffraction pattern for particle s8 (identified as $\mathrm{MgZn}_{2}$ ).

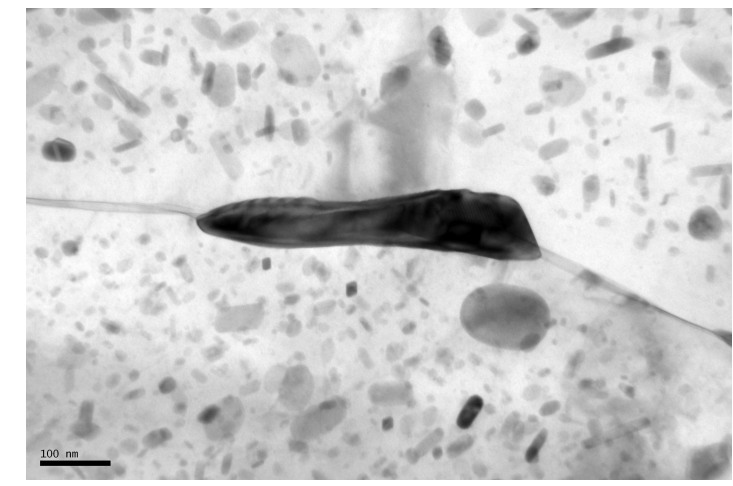

(a)

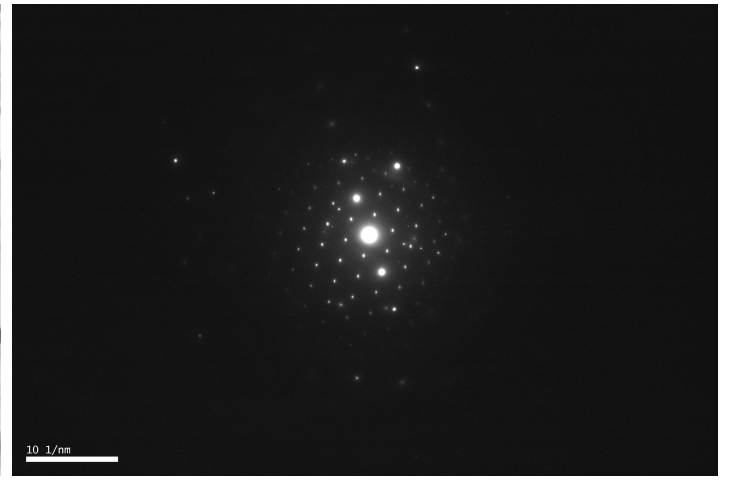

(b)

Figure 5.4: The results of TEM EDX, showing (a) a grain boundary particle and (b) the diffraction pattern for the grain boundary particle (identified as $\mathrm{Al}_{2} \mathrm{Cu}$ ).

An estimation of $\mathrm{MgZn}_{2}$ particle size and inter-particle spacing for each sample (as-received and 24 hours, 75 hours and 400 hours soak at $200^{\circ} \mathrm{C}$ ) was determined through the post processing of TEM images using ImageJ. Figure 5.5 shows resulting (fitted) Weibull distributions for particle size and interparticle spacing. A clear increases in spacing and size is noted, with a strong correlation to the decrease in the monotonic yield stress of the material with soak time (see figure 5.5 (c)). It is suggested here that the increase in $\mathrm{MgZn}_{2}$ particle size and inter-particle spacing due to ageing results in fewer obstacles to dislocation motion, thereby reducing the apparent material yield strength. Although particle size and spacing measurements are not used in the phenomenological model developed in the present work, it is the intention of the authors that the observations made here will assist in the future development of physically based models. Furthermore, the microstructural observations made here indicate some physical underpinning for the evolution of $R_{a}$, and suggests that the initial value of $R_{a}$ represents the capacity for larger internal stresses caused by dispersed precipitate obstacles. 


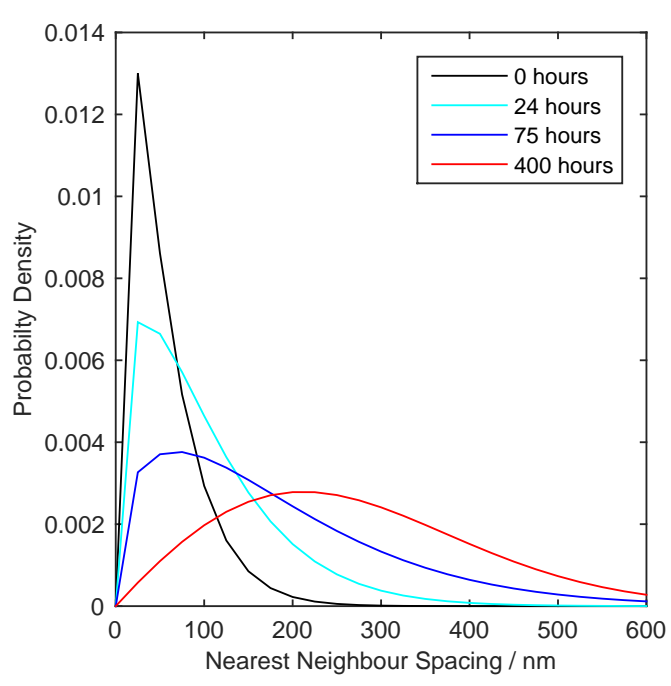

(a)

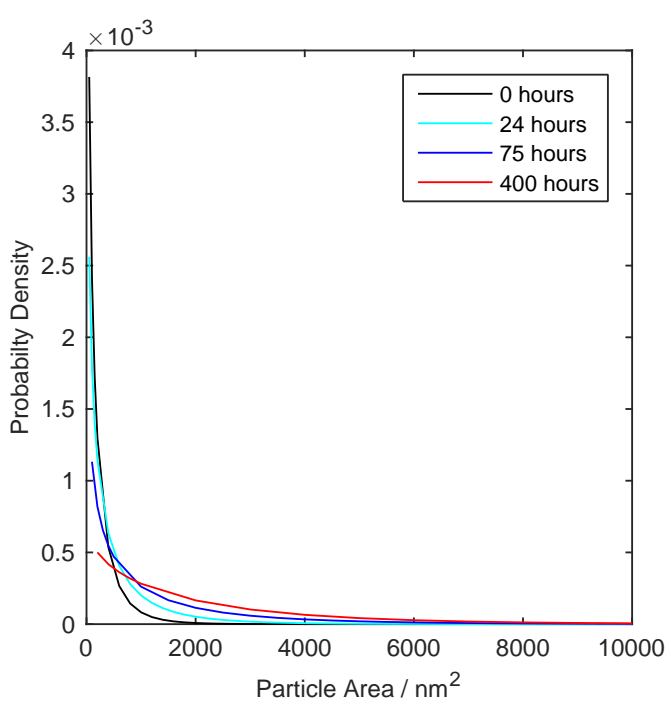

(b)

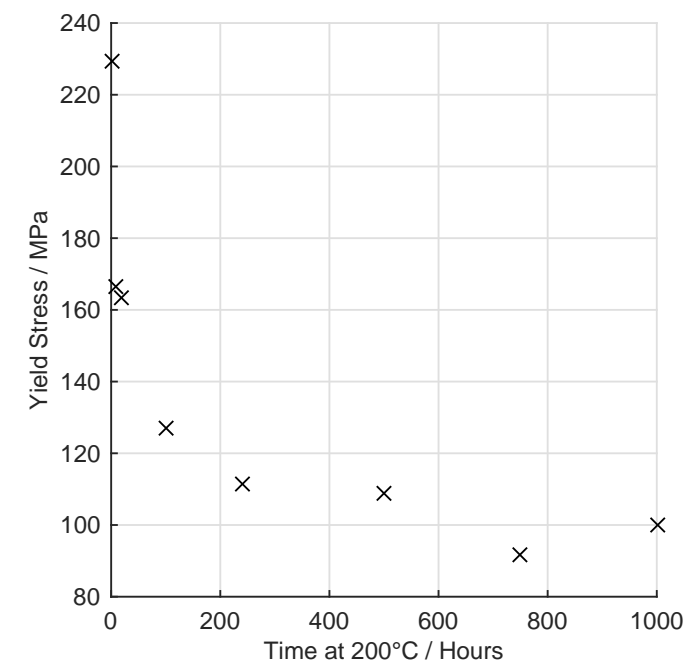

(c)

Figure 5.5: A comparison of the distribution curves of (a) the inter-particle spacing between the four nearest neighbours and (b) the particle size. (c) The monotonic yield stress after 1000 hours of soaking at $200^{\circ} \mathrm{C}$.

\section{Discussion and Conclusions}

The work presented here has focused on the development of a unified elastic viscoplastic material model which is capable of describing the response of a 7175-T7351 aluminium alloy under conditions where it rapidly ages. Experimental data used in this process considered sock/test temperatures that were representative of aerospace gearbox housing operating conditions (namely $160^{\circ} \mathrm{C}$ and $200^{\circ} \mathrm{C}$ ). The observation of rapid material ageing at these industry relevant temperatures suggests that a detailed understanding of how this material's strength evolves during freak operation condition excursions is important from a design perspective. A novel load waveform was used in experimental studies to provide relevant material response data which captures the hardening behaviour of the material. The developed model was able to accurately predict the material behaviour under strain-controlled fully-reversed isothermal cyclic plasticity conditions at $160^{\circ} \mathrm{C}$ and $200^{\circ} \mathrm{C}$. Results indicate that the model provides an accurate stress prediction of the as-received material data (with errors less than 
15\%) and highlighted a strong requirement on establishing accurate material parameters before the material ageing parameters are optimised. This is demonstrated in figure 4.1, where the predicted secondary mechanical softening region at $160^{\circ} \mathrm{C}$ rapidly diverges from the experimental data after 2000 cycles.

Prediction of the "partially-aged" test data and the "fully-aged" test data at $160^{\circ} \mathrm{C}$ and $200^{\circ} \mathrm{C}$ were carried out to validate the model. At $160^{\circ} \mathrm{C}$, the model provided a reasonable prediction of the stress response but a slight over-estimation in the stress amplitude and the yield strength. At $200^{\circ} \mathrm{C}$ the model exhibited good predictive capabilities to a high degree of accuracy, as shown by the $r^{2}$ coefficient and errors in maximum stress and plastic strain range. Overall, the model predictions agree well with the experimental data across the conditions investigated. The model proposed, to include a material ageing term, is therefore proven to be relevant and useful for the prediction of the material behaviour observed in the 7175-T7351 aluminium material.

An important novel aspect of the present work is the use of a time dependent isotropic hardening term $\left(R_{a}\right)$ to account for thermal ageing in the 7175-T7351 aluminium material. Linearly partitioning isotropic into mechanical (plastic strain associated) and ageing components appears to be a promising approach in describing the cyclic response of materials which exhibit rapid thermal ageing characteristics. The effect of $R_{a}$ is summarised below in figure 6.1, where predicted material responses from models with and without active ageing terms are compared to experimental data $\left(200^{\circ} \mathrm{C}\right.$ cyclic plasticity with no prior ageing). It can be see in these figures that stresses are consistently under predicted in the model with no active ageing term, however this discrepancy decreases as the $R_{a}$ contribution becomes less and less. It is important to note that the response predicted by the model with no active thermal ageing is not identical to the mechanical component of the full model, even though both use the same material parameters. This is due to linear summation of thermal and mechanical terms is the isotropic (drag) stress $R$. With no active ageing term, significantly more plasticity is accumulated in the first loading cycles, thereby prompting a more rapid evolution of conjugate variables.

Experimental and data processing techniques have been described in the present work which are suitable for the investigation of rapid thermal ageing. A simple cyclic plasticity model has been adopted here, however it should be noted that it could be developed considerably in the future by considering alternative viscous stress formulations (which are capable of accounting for a wider range of loading rates, for example sinh formulations). Ratcheting predictive capability should also be investigated. 


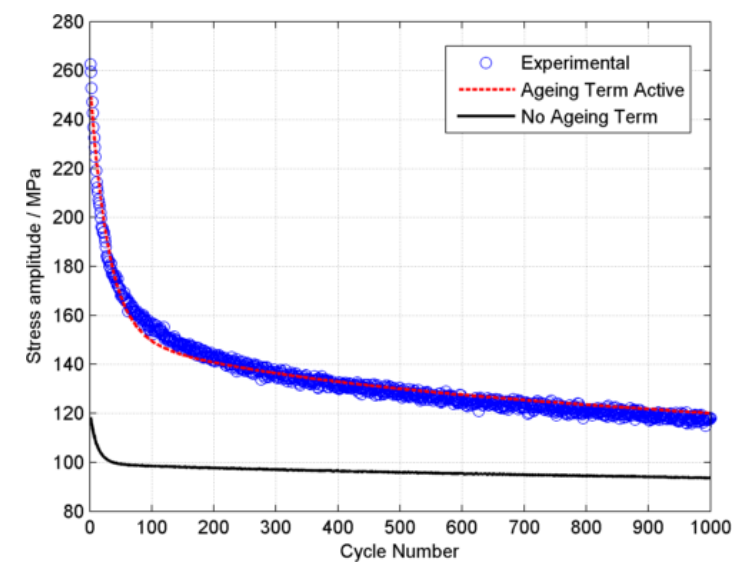

(a)

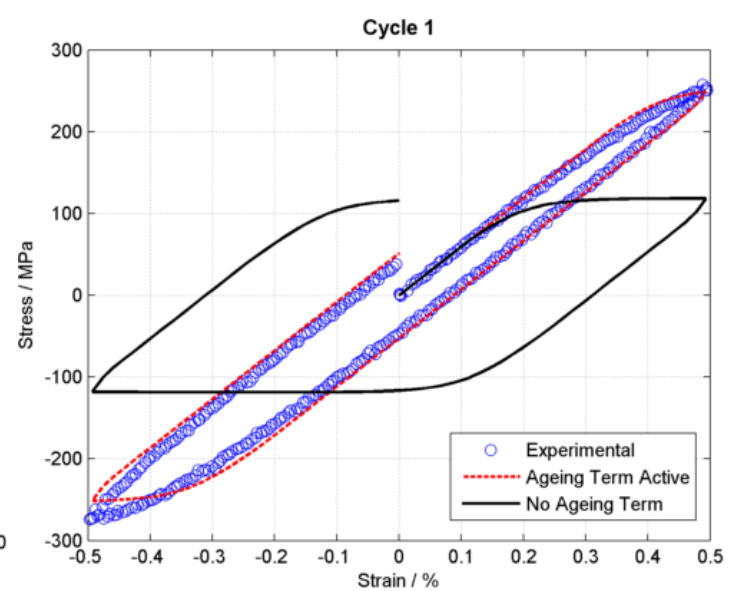

(b)

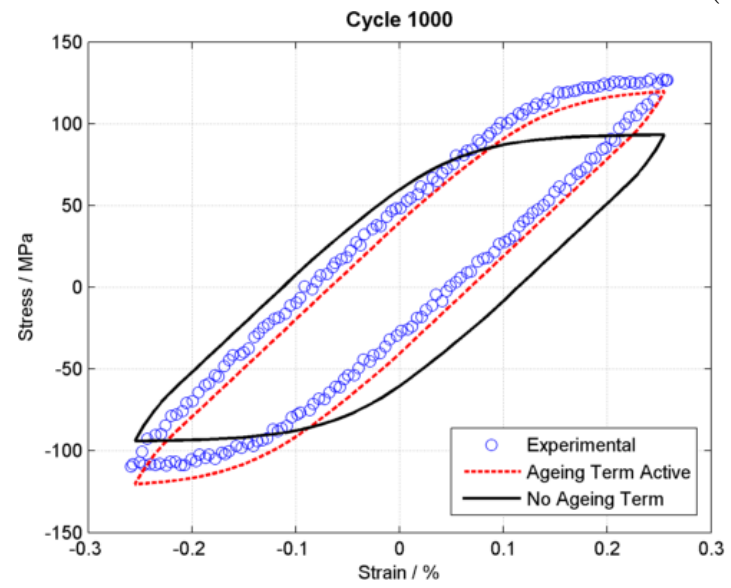

(c)

Figure 6.1: Predicted stress responses for a specimen tested at $200^{\circ} \mathrm{C}$ with no prior ageing. Predicted behaviours are shown for a model which has an active thermal ageing term $\left(R_{a}\right.$, as described above) and a model where this term is neglected. Responses are presented for (a) the cycle softening behaviour, (b) cycle 1, and (c) cycle 1000.

\section{Bibliography}

[1] ACARE. Strategic research \& innovation agenda 2017 update. ACARE. 2017;.

[2] Zhao T, Jiang Y. Fatigue of 7075-T651 aluminum alloy. International Journal of Fatigue. $2008 ; 30(5): 834-849$.

[3] Immarigeon JP, Holt RT, Koul AK, Zhoa L, Wallace W, Beddoes JC. Lightweight materials for aircraft applications. Materials Characterization. 1995;35(1):41-67.

[4] Atiik E, Meric C, Karlik B. Determination of yield strength of 2014 aluminium alloy under ageing conditions by means of artificial neural networks method. Mathematical \& Computational Applications1. 1996;1(2):16-20.

[5] Shriwas AK, Kale VC. Impact of aluminum alloys and microstructures on engineering properties review. IOSR Journal of Mechanical and Civil Engineering. 2016;13(3):16-22.

[6] Chaboche JL, Rousselier G. On the plastic and viscoplastic constitutive equations - part 1: rules 
developed with internal variable concept. Journal of Pressure Vessel Technology. 1983;105(2):153 158.

[7] Baushinger J. On the change of the positions of elastic limit or iron and steel under cyclic variation of stress. Mitt Mech - Tech Lab, Munich. 1886;13.

[8] Marquis D, Lemaitre J. Constitutive equations for the coupling between elasto-plasticity damage and aging. Revue De Physique Appliquee. 1988;23:615 - 624.

[9] Cailletaud G, Depoid C, Massinon D, Nicouleau-Bourles E. Elastoviscoplasticity with ageing in aluminium alloys. Continuum Thermomechanics. 2000;p. 75-86.

[10] Chaboche JL, Rousselier G. On the plastic and viscoplastic constitutive equations - part 2: application of internal variable concepts to the 316 stainless steel. Journal of Pressure Vessel Technology. 1983;105(2):159 - 164 .

[11] Armstrong PJ, Frederick CO. A mathematical representation of the multiaxial bauschinger effect. Materials at High Temperatures. 2007;24(1):1-26.

[12] Hyde CJ, Sun W, Leen SB. Cyclic thermo-mechanical material modelling and testing of 316 stainless steel. International Journal of Pressure Vessels and Piping. 2010;87(6):365-372.

[13] Kyaw ST, Rouse JP, Lu J, Sun W. Determination of material parameters for a unified viscoplasticitydamage model for a P91 power plant steel. International Journal of Mechanical Sciences. 2016;115116:168-179.

[14] Rouse JP, Hyde CJ, Sun W, Hyde TH. Effective determination of cyclic-visco-plasticity material properties using an optimisation procedure and experimental data exhibiting scatter. Materials at High Temperatures. 2013;30(2):117-128.

[15] Guillaume P, Pintelon R. A Gauss-Newton like Optimisation Algorithm for "Weighted" Nonlinear Least-Squares Problems. IEEE Transactions on Signal Processing. 1996;44:2222-2228. 